\title{
ESTUDO DA CAPACIDADE GERAL DE COMBINAÇÃO EM MILHO
}

\author{
MARIO PONT MEZZACAPPA \\ Assistente da Seção de Genética da Esc. Sup. de Agric. \\ "Luiz de Queiroz"
}

\begin{abstract}
fNDICE
1 - Introdução $\ldots \ldots \ldots \ldots$

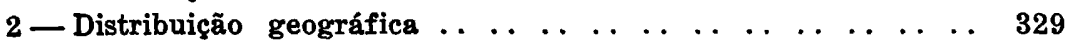

3-Métodos de Melhoramento .. .. . . . . . . . . . . . . . . . 331

4 - Material e Métodos . . . . . . . . . . . . . . . . . . . . . . 338

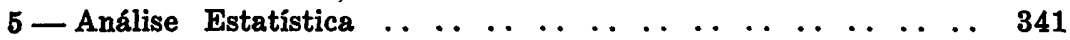

Resumo e Conclusões ......................

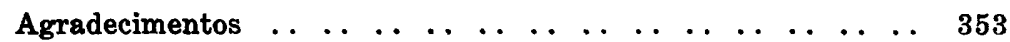

Bibliografia . . . . . . . . . . . . . . . . . . . . . . . . . .
\end{abstract}

Tese para doutoramento, apresentada à Escola Superior de Agricultura "Luiz de Queiroz" da Universidade de São Paulo em 30 de Outubro de 1951, e aprovada pela banca examinadora constituida pelos professores : Dr. F. G. Brieger, Dr. Edgard do Amaral Graner e Dr. José T. do Amaral Gurgel. 


\section{1 - INTRODUÇÃO}

Nos modernos métodos de melhoramento de milho, antes de as linhagens puras serem associadas em híbridos a fim de que sejam restabelecidos o vigor e a produtividade, torna-se necessário avaliar as capacidades geral e específica de combinação. Nêste trabalho visamos, principalmente, a capacidade geral de combinação, enquanto que a capacidade específica $d \epsilon$ combinação será objeto de futuro estudo.

A fim de tornar mais claro êste ponto, citaremos, resumidamente, a marcha a ser seguida na elaboração de um programa de melhoramento.

Em primeiro lugar, torna-se necessário estabelecer um padrão que apresente as principais características agronômicas e comerciais exigidas, e que sirva de base aos trabalhos posteriores. Em segundo lugar devemos conhecer perfeitamente a matéria prima utilizada no melhoramento, quer seja esta de origem nacional ou estrangeira. A terceira fase do processo de melhoramento visa a obtenção de novos tipos altamente produtivos e que correspondam, o mais possível, ao padrão preestabelecido.

\section{1 - Estabelecimento do Tipo Padrão}

Se voltarmos nossos olhares para os Estados Unidos, onde o melhoramento do milho vem sendo desde há muito praticado. pode nos parecer que a escolha do padrão não oferece dificuldades.

Entretanto, entre nós, a situação é bastante diversa, pois os nossos dois principais tipos cultivados, isto é, o Cateto e o Dente, apesar de não apresentarem grandes diferenças quanto às exigências da lavoura, diferem grandemente sob o ponto de vista comercial, motivo pelo qual abordaremos, resumidamente, as principais exigências do mercado e da lavoura.

1.1.1. - Exigência do mercado. Nêstes últimos anos, parece estar se processando uma profunda modificação nas exigências do mercado, pois, antigamente, emprestava-se maior atenção aos tipos duros alaranjados, enquanto hoje se nota uma crescente preferência para as variedades indentadas, menos duras. Cêrca de dois terços da área paulista cultivada com milho o são com o tipo Dente, segundo a Palestra proferida pelo eng. agr. JOSE' ANDRADE Sobr., do Instituto Agronômico de Campinas, na 1a. Semana do Agricultor, realizada na Escola Superior de Agricultura "Luiz de Queiroz", em 1950. 
O Cateto, além de corresponder ao tipo de exportaçăo cesde há muito estabelecido pela República Argentina, apresenta vantagens sôbre o ponto de vista industrial, pois, não ha perda de endosperma durante a extração do pericarpio, enquanto o Dente, embora mais produtivo, é utilizado, principalmente, na alimentação dos animais domésticos nas próprias fazendas.

1.1.2. - Exigências agronômicas. Entre outras, citaremos alguns característicos morfológicos de grande importância agronômica na cultura desta utilissima gramínea.

Plantas muito altas e com espigas mal localizadas sôbre o colmo podem dificultar a colheita manual ou mecânica e, ainda, facilitar o acamamento.

Uma bôa planta, sob êsse ponto de vista, seria aquela que apresentasse cêrca de 2 metros desde o chão até a base da fle$\mathrm{xa}$, e tivesse a espiga localizada no colmo, mais ou menos a1 ou $1,20 \mathrm{mt}$ de altura.

A tabela 1 nos dá uma idéia da grande variação dentro do grupo dos Catetos, relativamente à altura da planta e inserção da espiga sôbre o colmo.

As plantas devem ser vigorosas, com sistema radicular e panículas bem desenvolvidos, imunes, ou pelo menos, resistentes às pragas e moléstias. Carlos T. Mendes (1) atribue grande importância a coloração verde intensa das plantas; convém entretanto mencionar que nos E. U., algumas linhagens de coloração fraca apresentam ótima capacidade de combinação.

Entre nós, atribui-se pouca importância às pragas e moléstias, pois, geralmente, elas não constituem sérios problenas, a não ser em casos especiais, como o de um dos híbridos simples de Campinas, que fôra totalmente aniquilado pelo percevejo castanho (Scaptecoris castaneus), devido ao fato de uma de suas linhagens ser susceptível ao ataque do mencionado inseto, conforme noticia publicado no "Estado de S. Paulo". Parece que esta praga não era comum no local onde foi confecionadc o mencionado híbrido simples e o problema da falta de resistência apenas surgiu quando o híbrido foi cultivado em uma nova região, ou seja em Sertãozinho.

Outro característico agronômico de grande importância é a precocidade, pois, como sabemos, algumas variedades são mais precoces e outras, mais tardías. Dentro de um mesmo grupo, entretanto, pode haver grande variação, quanto a precociaade, como podemos observar na tabela 1 . 


\begin{tabular}{|c|c|c|c|}
\hline VARIEDADES & $\begin{array}{c}\text { Floresci- } \\
\text { mento }\end{array}$ & $\begin{array}{c}\text { Altura da } \\
\text { planta }\end{array}$ & $\begin{array}{c}\text { Altura } \\
\text { espiga }\end{array}$ \\
\hline $\begin{array}{l}\text { Quarentão } \\
\text { (Original da R. Argentina) } \\
\text { Colorado } \\
\text { (Original da R. Argentina) } \\
\text { P - } 138 \\
\text { (Original do R. G. do Sul) } \\
\text { P - } 139 \\
\text { (Original de São Paulo) } \\
\text { P - } 140 \\
\text { (Original de São Paulo) }\end{array}$ & $\begin{array}{l}58 \text { dias } \\
60 \text { dias } \\
68 \text { dias } \\
74 \text { dias } \\
84 \text { dias }\end{array}$ & $\begin{array}{l}134,00 \mathrm{~cm} \\
134,97 \mathrm{~cm} \\
158,18 \mathrm{~cm} \\
208,00 \mathrm{~cm} \\
201,00 \mathrm{cir}\end{array}$ & $\begin{array}{r}43,00 \mathrm{~cm} \\
48,37 \mathrm{~cm} \\
81,36 \mathrm{~cm} \\
111,00 \mathrm{~cm} \\
105,00 \mathrm{~cm}\end{array}$ \\
\hline
\end{tabular}

A precocidade, nêstes casos, foi avaliada pelo número de dias decorriòos desde a semeação até o aparecimento das barbas, isto é, dos estilos-estigmas. Além dos característicos mencionados, poderíamos acrescentar outros menos importantes, tais como: largura da fôlha, número de internódios, etc.

E' interessante notar que há uma certa associação entre a altura de planta e precocidade, sendo as plantas mais baixas as mais precoces.

Devemos, ainda, considerar certos característicos relacionados à morfologia da espiga, tais como, forma, número de fileiras, relação sabugo-grãos, etc.

\section{2. - Matéria Prima}

Uma vez cientes das exigências do mercado e da lavoura, devemos escolher os tipos ou variedades que servirão de base aos nossos trabalhos de melhoramento; fazemos, para isso, um levantamento do material existente na região, pois qualquer método fitotécnico inclui, sempre, a necessidade de se procurarem novas fontes de variação, a fim de que sejam obtidos novos caracteres agronômicos desejáveis. Podemos, também, recorrer a material de outras regiões do país, ou, mesmo, importar variedades estrangeiras, razão pela qual daremos, a seguir, resumidamente, a origem e a distribuição geográfica das variedades Dente e Cateto.

Segundo BRIEGER (2), os Catetos devem ser originários da região do mar das ilhas Caraíbas ou da zona limítrofe da América Central e do Sul, tendo, posteriormente, se espalhado em direção sul, nas regiōes costeiras do Atlântico, e penetrado mais ou menos profundamente continente a dentro. 


\section{2 - DISTRIBUIÇÃO GEOGRAFICA}

BRIEGER (3), em contribuição apresentada ao $1^{\circ}$. Congresso Latino-Americano de Fitogeneticistas realizado no México, admitiu que os tipos duros alaranjados se distribuem na Costa do Atlântico, desde a bacia do Plata, até mais ou menos a aliura do Rio de Janeiro; uma segunda área de distribuição dessa variedade é encontrada mais ao norte, desde a fóz do Amazonas até as ilhəs Caraibas. Na zona intermediária, isto é, entre o Rio de Jan eiro e a fóz do Amazonas, o Catêto não é encontrado puro, mas mesclado com milho Dente norte-americano ou indígena.

Os Catetos do Rio da Plata podem ser divididos em dois grupos :

a) Quarentão

b) Colorado

O Quarentãc é de porte mais baixo, e um pouco mais precoce que o (c:lorado (ver tabela 1). Suas espigas são cilíndricas, com malcr número de fileiras, grãos menores, muito juntos, enquanto que o Colorado apresenta espigas mais compridas, com menor número de fileiras e grãos arredondados.

No Uruguay, segundo informações verbais do Dr. Ponce de León, o Quarentão e o Colorado podem ser colhidos, respectivamente, com 120 e 160 dias após a semeadura. Entre nós, isto é, na Secção de Grenética, entretanto, êsses mesmos tipos são (i)lhidos, com, aproximadamente, 95 ou 100 dias.

No Rio Grande do Sul, é cultivado um outro tipo de Catêto sob a denominação de Assis Brasil.

BRIEGER acha que se trata de uma raça smtética, resultante de cruzamentos entre Cateto comum de S. Paulo, Rio de Janeiro, Minas, etc., com milho indígena amarelo-mole, dos Guaranís. Esse tipo sul-riograndense, quando cultivado entre nós, é mais ou menos intermediário entre os tipos paulista, argentino e uruguaio, quanto a altura das plantas e precocidadcs.

Suas plantas são muito vigorosas, relativamente baixas, com espigas inseridas a uma bôa altura sôbre o colmo. As uspigas são longas, cilíndricas, com fileiras retas e grãos muito grandes, menos duros que os demais tipos de Cateios.

Apesar de alta produção e outros característicos agronômicos favoráveis, apresenta dois graves defeitos:

a) Palha curta.

b) Falta de coincidência em algumas linhagens entre o aparecimento das barbas e deiscência das anteras, ou melhor, os estames chegam a maturidade antes que os órgãos femininos 
possam ser fecundados. Estamos pois em presença de um caso de protandria.

Os Catetos de nossa região são menos precoces e apresentam plantas mais altas que os tipos do sul. Suas espigas possuem. tendência para a forma cônica e os seus grãos são, também, menores.

Possuimos, aindá lim outro tipo de Cateto cultivado no Norte do Brasil pelos indios Pariucur, Galibí, etc., trazido pelo docente livre da Seção de Genética, Dr. W. E. Kerr, e que, exceto na coloração, que é pouco mais clara que a dos nos ios tipos, corresponde às vari đades por nós cultivadas.

Outros tipos coletados pelo Prof. BRIEGER, na Colômbia e na Guatemala, e que enriquecem a coleção da Seção de Genética, por serem de clima mais tropical e cultivados a maiores altitudes, não parecem ser muito promissores.

Relativamente ao milho dente, muito importante na lavoura, limitar-nos-emos a poucas referências, pois não é objeto dêste trabalho.

BRIEGER (3) distingue dois tipos: a) Dente duro, que tem seus centros de maior diversidade no México e Estados Unidos; b) Dente-mole, cujo melhor representante é s Dentebranco, cultivado pelos índios Kaingang, no sul do Brasil.

De acôrdo ainda, com referências do mesmo autor, os Dentes amarelos norte-americanos, de origem relativamente recente, resultaram de cruzamento acidentais entre "North-eastern Little Flint", tipo muito precoce, originalmente cultivado pelos índios do leste do Canadá e Nordeste dos Estados Unidos, e o "Gourd Seed", um Dente branco da América Central, que se disseminou no sul dos Estados Unidos, como foi comprovado por documentação histórica. O "Reids Yellew Dent", segundo PAUL DE KRUIFF (4), também resultou de um cruzamento acidental entre o "Little Yellow" e o "Gorden Hopkins".

No Brasil houve introdução de Dente norte-americano em várias \& pocas; entretanto, essas variedades não se cornpcrtaram bem entre nós, e tôdas as tentativas parı! sua aclimação foram infrutíferas.

Lim dos fatores, que segundo tudo indica impede a aclimataçin entre nós de material dos E. U. ou Canadá ou de outras regijes onde os dias são sials longos, é (, frioteriodismı, pnis es cias em nosso Estado s. mais curtos.

Essa diferença no número de horas de insolação pode causar disturbios fisiológicos às plantas, que multas vezes morrem antes de completarem o ciclo vegetativo e, devido a isso, as espigas não se desenvolvem convenientemente e os grãos não chegam à maturidade. As nossas variedades mais antigas como 
Armour, Pinhal, Amparo, Sta. Rosa, etc., são muito provavelmente variedades sintéticas, naturais, provenientes de cruzamentos entre milho Dente norte-americano e J nosso Catêto, exceção feita ao Sta. Rosa, onde parece entrar tainbém, o Kaingang.

\section{3 - METODOS DE MELHORAMENTO}

Escolhidos o tipo padrão e a matéria prima podemos começar os trabalhos de melhoramento, desde que a variedade eleita possua os caracteres desejáveis. Caso contrário, devemos reunir, por cruzamentos, caracteres de diferentes variedades.

Ultimamente, em nosso país, estão sendo recomendados híbridos entre as variedades Dente e Catêto, não só pelo fato de serem menos duros que os constituidos apenas por linhagens de Catêto, mas, também, por possuirem plantas mais baixas, espigas cilíndricas, e, sobretudo, maior produção.

Achamos, entretanto, que tais híbridos por possuirem menor homogeneidade, constituem apenas uma solução provisória, enquanto não possuimos híbridos exclusivamente Dente.

As plantas eleitas serão, a seguir, submetidas a uma série de autofecundações, cuja finalidade é a obtenção de linhagens puras.

Como o milho perde, mais ou menos ràpidamente, o seu vigor, quando reproduzido por autofecundação, torna-se necessário, para o estabelecimento do vigor e produtividade, recorrermos a cruzamentos entre as linhagens autofecundadas. Entretanto, antes de efetuarmos os cruzamentos, devemos procurar conhecer a capacidade geral e a específica de combinação das linhagens, pois delas depende a produção dos híbridos.

\section{1. - Capacidade de Combinação}

Capacidade geral de combinação é o comportamento médio de uma linhagem em combinações híbridas.

A capacidade específica de combinação tem por finalidade conhecer certas combinações especiais que podem ser superiores ou, mesmo, inferiores ao valor médio determinado pela capacidade geral de combinação.

BRIEGER distingue, ainda, a capacidade geral de combinação da variedade, que pode ser avaliada por cruzamentos, com uma variedade ou tipo padrão.

Como o isolamento de linhagens que apresentam características agronômicas desejáveis e que combinadas formem hí- 
bridos de alta produção tem constituido uma das mais sérias preocupações nos trabalhos de melhoramento de milho, faremos, a seguir, um breve resumo da literatura quanto à capacidade geral de combinação.

A princípio, atribuiu-se grande importância aos caracteres morfológicos e à produtividade das linhas durante o processo de autofecundação.

Assim KIESSELBACH (5) mostrou haver correlação entre a produção das linhas autofecundadas e seus híbridos.

RICHEY (6) observou que certas linhas em híbridos transmitiam a seus descendentes a alta capacidade de produção.

RICHEY e MAYER (7) não só confirmaram tal fato, mas mostraram também, que híbridos de linhagens, com 5 autofecundações, não apresentavam grandes vantagens sôbre os constituidos por famílias apenas 3 vêzes autofecundadas.

HAYES (8) segundo SPRAGUE (9) e HAYES e IMMER (10) mostrou que certos caracteres relacionados ao vigor eram positivamente correlacionados com a produção.

NILSSON - LEISSNER (11) encontrou, também, correlação entre certos caracteres morfolóficos relacionados ao vigor e produção das linhas autofecundadas e os mesmos caracteres em seus híbridos.

JORGENSON e BREWBAKER (12), além de encontrarem correlação entre certos caracteres morfológicos das linhas autofecundadas e os mesmos característicos em seus híbridos, observaram, também, que as famílias mais vigorosas apresentavam maior capacidade de produção; notaram ainda, que algumas linhagens de alta produção nem sempre produziam bons híbridos. Os caracteres em estudo foram : produção, comprimento e diâmetro da espiga, número de fileiras, altura da planta, etc.

JENKINS (13) achou correlação entre a produção das linhas autofecundadas e o rendimento de seus híbridos. Verificou, ainda, que certos caracteres como altura da planta, camprimento e diâmetro da espiga, etc., eram correlacionados positivamente com a produção.

BRIEGER e GRANER (14) admitem que "a altura e posição da espiga são caracteres que parecem de grande importância prática. As plantas extremamente altas tem, no geral, uma haste muito forte e folhas bem grandes, mas êste vigor da planta parece conforme nossas experiências preliminares, ser independente da produção das sementes".

HAYES e JOHNSON (15) encontraram correlação entre as produções de cruzamentos linha $\mathrm{x}$ variedade e vários caracteres das linhas autofecundadas. Alguns dos caracteres eram os seguintes: data de aparecimento da barba, altura da plan- 
ta, comprimento da espiga, superfície foliar, volume do sistema radicular, diâmetro da haste, produção de polem, etc.

Êsses resultados demonstraram haver vantagem em selecionar linhas autofecundadas vigorosas, não só pela maior produção de sementes mas, também devido ao maior rendimento dos híbridos duplos.

3.1.1. - Teste das linhagens autofecundadas. Após a obtenção de linhagens puras, devemos saber como proceder na obtenção de híbridos, que, além de característicos agronômicas desejáveis, apresentem, também, uma maior produção.

No início dos trabalhos de melhoramento, a seleção das linhas puras era baseada no comportamento médio de todos os possíveis cruzamentos simples entre elas. Esse processo, entretanto, é muito trabalhoso, pois, quando temos $m$ linhas autofecundadas, deveremos estudar e comparar híbridos simples. (

Necessário se tornou, então, o emprêgo de métodos mais simples na seleção das linhagens puras.

JONES (16) utilizou o processo de cruzamento linha $x$ variedade não propriamente com o propósito de avaliar a capacidade geral de combinação, mas sim com o intuito de verificar o comportamento relativo das linhagens nesses cruzamentos. DAVIS (17) lançou mão dêsse processo para avaliar a capacidade de combinação de linhas S2.

O cruzamento linha $\mathrm{x}$ variedade ou "top-cross" consiste no cruzamento de linhagens autofecundadas com uma variedade comercial. A variedade comercial pode ser a mesma que deu origem às linhas autofecundadas ou outra qualquer. Podemos ainda utilizar híbridos simples, duplos ou variedades sintéticas.

LINDSTROM (18) também observuu o comportamente de linhagens em "top-cross", e surgiu o seu emprêgo na lavoura.

JENKINS e BRUNSON (19) comparando a eficiência da avaliação da capacidade geral de combinação pelo processo de "top-cross", linhagens "testers" e por meio de todos os cruzamentos simples possíveis, obtiveram dados que justificam o emprêgo de cruzamentos linha $\mathrm{x}$ variedade na seleção das linha autofecundadas.

JOHNSCN e HAYES (20), comparando o método de "topcross" com o de todos os cruzamentos possíveis entre as linhas autofecundadas, encontraram, também, dados que justificam a utilização In primeiro processo na avaliação da capacidade geral de combinação; sugeriram, então, que os cruzamentos linha $\mathrm{x}$ variedade constituem um método rapido e eficiente para se 
avaliar a capacidade de produção das linhagens autofecundadas em combinações híbridas.

SPRAGUE @ TATUM (21), acham que o cruzamento linha $\mathrm{x}$ variedade deve ser empregado para avaliar a capacidade geral de combinação, enquanto que a determinação da capacidade específica de combinação deve ser feita por meio de híbridos simples.

3.1.2 - Seleção genética. Êsse processo para testar a capacidade geral de combinação foi proposto por STADLER, segundo SPRAGUE (9) e HAYES, RINKE e TSIANG (22).

As plantas de uma variedade comercial são cruzadas com uma linhagem pura de ótimas qualidades. Êsses "top-crosses", no ano seguinte, serão cruzados com outra linhagem "tester". As duas linhagens puras, por sua vez, são combinadas em hibridos simples. Todos os híbridos que excederam ao híbrido simples constituido pelas duas linhas puras devem ter recebido do gameta derivado da variedade comercial um conjunto supericr de gens para alta produção.

3.1.3 - Seleção recíproca recorrente ("Recurrent reciprocal selection").

COMSTOCK, ROBINSON e HARVEY (23) propõem a avaliação das capacidades geral e específica de combinação durante o período de homogenização das linhagens, por meio da seleção recíproca recorrente.

3.1.4 - Herança da capacidade de combinação : Diversidade Genética - JONES e SINGLETON (24), após notarem que certas linhagens têm um efeito mais favorável na produção que outras, reuniram-nas em 3 categorias : linhagens de alta produção, produção média e de baixa produção.

Em nenhum caso os maiores rendimentos foram obtidos por linhas de baixa produção; porém, em 3 ocasiões, os maiores e menores rendimentos foram conseguidos por linhas de produção média.

Híbridos duplos com uma, duas ou três linhas de alta produção, poucas vantagens mostraram sôbre aquêles que não apresentavam nenhuma linhagem de alta produção. Os outores só possuiam 3 linhas de alta produção, motivo pelo qual híbridos duplos com 4 linhas de alta produção não foram feitos.

Dêsses dados, concluiram, ser impossível predizer a produção das linhagens, sem, antes, testá-las.

HAYES e JOHNSON (15) notaram que, quando duas linhagens de alta capacidade de combinação eram cruzadas, as novas linhas isoladas por autofecundação apresentavam, também, alta capacidade de combinação. Progenitores de baixa ca- 
paciđade de combinação só davam descendentes de baixa capacidade de combinação.

Os descendentes de cruzamentos entre linhagens de alta e baixa capacidade de combinação segregaram para a capacidade de combinação..

Esses estudos mostram que a capacidade geral de combinação é um carater hereditário.

WU (25) e HAYES e JOHNSON (15), comparando o rendimento de híbridos constituidos por linhagens aparentadas e não aparentadas, mostraram a importância da diversidade genética na produção dos híbridos.

Foram estudados 3 grupos de linhas, reunidas de acôrdo com o seu parentesco, comparando-se os rendimentos dos híbridos simples, conforme a sua origem.

Êsses estudos mostraram que híbridos simples com um. dois, ou nenhum progenitor em comum diferiam grandemente em produção; os mais produtivos eram aquêles constituidos por linhagens não aparentadas, e os que apresentavam melhor rendimento eram os formados por duas linhagens aparentadas.

JOHNSON e HAYES (26), efetuando cruzamento só entre linhagens não aparentadas, chegaram à conclusão de que a diversidade genética do material é tão importante, senão mais importante que o capacidade geral de combinação.

As linhagens, de acôrdo com os cruzamentos linha $\mathrm{x}$ variedade, foram classificadas em dois grupos :

a) de alta capacidade de combinação;

b) de baixa capacidade de combinação.

Cruzamentos entre linhas de baixa capacidade de combinação renderam muito menos que entre alta $x$ alta e baixa $x$ alta. Entretanto, cruzamentos simples, entre linhas homogêneas de baixa e alta capacidade de combinação, mostraram ser tẫo produtivos quanto aos de alta capacidade de combinação, quando as linhas associadas eram de origem genética diferentes.

ECKHARDT e BRYAN (27), observaram que os rendimentos de híbridos duplos de linhas procedentes de duas variedades, eram sempre mais produtivos quando se combinavam nos híbridos simples duas linhagens derivadas da mesma variedade.

Assim, pois, se A e B, eram linhas de uma mesma variedade e $\mathrm{X}$ e $\mathrm{Y}$ de outra, os autores acima mencionados verificaram que o híbrido duplo $(\mathrm{AB})$ (XY) era mais produtivo que (AX) (BX) ou (AY) (BX).

3.1.5 - Prova de capacidade geral de combinação. Comumente, no processo de obtenção de linhagens puras, as plantas são autofecundadas num interregno de 3 a 5 anos, ao mesmo 
tempo que se faz uma seleção rigorosa entre e dentro das fam:lias, tendo por finalidade eliminar as linhagens e plantas indesejáveis.

Após êsse período de homogeneização, as famílias remanescentes são testadas para se avaliar a capacidade geral e a específica de combinação, a fim de serem utilizadas na confecção de híbridos de 3 ou de 4 linhas.

Convém frizar que, assim procedendo, numerosas linhas, antes de serem eliminadas, foram trabalhadas e mantidas durante 3 ou 5 gerações, determinando, por conseguinte, uma perda de tempo e material, o que, evidentemente, acarreta maiores despesas.

Procurou-se, então, um método mais rápido e menos dispendioso para a obtenção das linhagens puras.

DAVIS (28) mostrou que as linhas autofecundadas man. tém sua capacidade de combinação durante o processo de homogeneização.

JENKINS (29), comparando a capacidade geral de combição em 8 gerações sucessivamente autofecundadas, apresentou dados mostrando que as linhagens estabelecem sua individualidade quanto à capacidade geral de combinação já no início do processo de purificação, e que esta mantem-se pràticamente inalterável nas gerações seguintes; sugeriu, então, que o cruzamento linha $\mathrm{x}$ variedade poderia ser feito no início da processo de autofecundação.

SPRAGUE (30), testando plantas So, notou que havia grande variação entre os seus "top-crosses", o que permitia avaliar a capacidade geral de combinação de plantas que não foram, ainda, autofecundadas.

JENKINS (31), citado por RICHEY (32) verificou haver pouca variação entre plantas de progenies $\mathrm{S} 1$.

SPRAGUE e BRYAN (33), estudando linhagens com 4 autofecundações mostraram que elas segregavam para a capacidade de combinação, resistência às moléstias e acamamento. Ésses resultados conduziram aquêles cientistas à seguinte pergunta : deve a capacidade de combinação das linhas ser avaliada no início do processo de purificação, ou, posteriormente, quando as famílias chegarem à homozygose?

Pelo segundo processo somos obrigados a manter grande número de linhagens que posteriormente serão eliminadas, enquanto que, pelo primeiro método, logo de início, descartaremos as linhas indesejáveis; trabalhando com menor número de famílias, podemos aumentar o número de descendentes de cada linhagem e fazer uma seleção mais rigorosa entre as famílias mais vantajosas, ou, mesmo, dentro delas. 
SINGLETON e NELSON (34) trabalhando com milho doce não encontraram correlação entre as produções de linhagens S1, S2 e S3, e admitiram que a capacidade geral de combinação não pode ser testada antes de S3.

SPRAGUE (35), comprovou a eficiência do teste precoce (early testing) salientando, entretanto, que êle pode ser ineficiente quando a frequência de gens para um determinado caráter é relativamente baixa. Ao considerarmos o teste precoce, devemos, sempre, ter em mente que há grande diferença, quanto a capacidade geral de combinação entre as plantas de polinização cruzada, e que a seleção de amostras, baseada na capacidade geral de combinação de S0 (variedade) ou S1 (geração avançada), dá oportunidade a uma melhor seleção de que quando as plantas são escolhidas ao acaso, por simples seleção visual.

Devemos não nos esquecer, também, de que o teste precoce difere do processo usual no seguinte:

a) as plantas S0, ao mesmo tempo que são autofecundadas pela primeira vez, são testadas para se avaliar a capacidade geral de combinação;

b) a eliminação de muitas linhas após êsse primeiro teste permite maiores atenções às famílias S1 e S2, quando a oportunidade de seleção entre as linhas é muito maior.

Resumindo: pelo método comum são gastos de 10 a 12 anos desde a primeira autofecundação, até que um determinado híbrido duplo seja entregue ao mercado, enquanto que o teste precoce abrevia o processo.

Por êsse novo método, fazemos um primeiro "top-cross" entre as plantas S0 de uma variedade comercial ou S1 de uma geração avançada, eliminando-se as linhagens indesejáveis.

Essas linhagens, na geração S4, são novamente testadas por "top-cross". As linhas que exibirem alta capacidade de combinação nesses dois "top-crosses" são reunidas em híbridos simples para se avaliar a capacidade geral e específica de combina.. ção e fazer a previsão dos híbridos duplos.

RICHEY (32), grupando de maneira diferente e reanalisando os dados de JENKINS (29) admitiu que descartando as 5 piores linhas em S2 - S3, seriam iliminadas três de alta capacidade de combinação em S6 - S8.

Mostrou ainda que 7 melhores e 5 piores linhas em S6 - S8, diferiam em S4-S5, mas não diferiam em S1 ou em S2-S3.

O mesmo autor menciona ainda, dados não publicados, gentilmente cedidos pelo Dr. E. Broadus Brown, que revelam que o teste da capacidade geral de combinação em S1 é um critério tão bom, senão melhor que quando levado a efeito com plantas Sn. 


\section{4 - MATERIAL E MÉTODOS}

\section{1 - Material}

O matrial a ser estudado neste trabalho pertence ao grupo dos milhos duros alaranjados conhecidos nos Estados de São Paulo, Rio de Janeiro e Minas Gerais, por Catêtos.

Em tais variedades comerciais há predominância do endosperma córneo sôbre o endosperma mole. Convém, entretanto, salientar que a proporção de endosperma córneo para mole varia de uma para outra variedade; assim, por exemplo, entre os Catêtos que constituem a coleção da Seção de Genética, os mais duros são o Quarentão e o Colorado, enquanto o mais mole é o P-138, também por nós denominado Cateto do Rio Grande, devido à sua origem.

As espigas do Catêto geralmente têm menor número de fileiras que as do tipo Dente e apresentam ligeira tendência para a forma cônica. Há variedades comerciais como o Quarentão e Colorado que possuem a forma cilíndrica.

Os grãos dos Catetos são geralmente de tamanho médio, podendo, entretanto, variar de uma para outra variedade; assim, o Cateto do Rio Grande possue grãos muito grandes e o Quarentão, bastante pequenos.

A altura das plantas e das espigas também apresentam grartde variação de uma para outra variedade, assim como a precocidade.

4.1.1 - Catêto Marília P-139 - O Catêto de Marília, coletado no município que lhe empresta o nome pelo docente livre Dr. José T. do Amaral Gurgel, mostra as seguintes características :

Plantas com cêrca de $208 \mathrm{cms}$ de altura, espigas inseridas mais ou menos na parte média do colmo, isto é, a $111 \mathrm{cms}$ do solo; sistema radicular e panicula bem desenvolvidos; coloração verde intensa e grande resistência às pragas e moléstias; tendência para produzir duas espigas mais ou menos cilindricas e bem cobertas de palha.

As espigas com cêrca de $18 \mathrm{cms}$ de comprimento, em média, quando despalhada, pesam 155 grs; possuem de 14 a $16 \mathrm{fi}$ leiras retas; cem grãos pesam 26 grs.

4.1.2 - Catêto Ipanema P-140 - Coletado no município de Ipanema e também introduzido em 1945 pelo docente-livre Dr. José T. do Amaral Gurgel, tem as seguintes características :

Plantas pouco mais baixas que o cateto Marília, com cêrca de $201 \mathrm{cms}$ de altura. Espigas localizadas no colmo, a $105 \mathrm{cms}$ do solo; sistema radicular bem desenvolvido; resistência ao a- 
camamento, às pragas e moléstias. O seu colmo é mais fino que o da variedade anterior.

Suas plantas, com panículas pouco menores que as do grupo anterior, apresentam, também, tendência para produzir duas espigas, se bem que menores que as do tipo Marília, com cêrca de $17 \mathrm{cms}$ de comprimento e um pêso médio de 136 gramas por espiga.

As espigas possuem fileiras retas de grãos, mostrando porém, uma dilatação na base e pronunciada tendência para a forma cônica. $O$ número de fileiras varia, em média, de 14 a 16. Seus grãos são menores que os do tipo precedente, com um pêso médio de 23 grs por 100 grãos.

4.1.3 - Quarentão - Nêste grupo estão incluidas as variedades comerciais coletadas no Uruguai e na Argentina, trazidas e introduzidas nesta Seção pelo docente-livre Dr. Ciro Marcondes Cesar e Prof. F. G. Brieger, em 1945.

Foram feitas várias introduções; os únicos remanescentes, depois de uma seleção rigorosa, são o Quarentão La Estanzuela e o Henrique Klein, pois os demais não se portaram bem entre nós.

De todos os Catêtos que constituem a coleção da Seção de Genética, o Quarentão apresenta porte mais baixo. Suas plantas possuem, em média, $134 \mathrm{cms}$ de altura e as espigas estão localizadas a mais ou menos $43 \mathrm{cms}$ do solo.

Seu sistema radicular é menos desenvolvido que o dos tipos anteriores. E' também resistente ao acamamento, às pragas e moléstias. Deve ser colhido na época certa, isto é, cêrca de 30 a 40 dias após a polinização, pois suas hastes são finas e decompõem-se com relativa facilidade. Suas plantas também são coloridas de verde intenso e as panículas estão de acôrdo com o tamanho das mesmas.

As espigas são cilíndricas, com fileiras retas e grãos muito pequenos, sendo que 100 grãos pesam, em média, 18 gramas.

A coloração laranja dos grãos é bem mais intensa que a dos tipos anteriores.

Era nossa intensão ilustrar o presente trabalho com fotografias coloridas; entretanto, devido às dificuldades técnicas encontradas, deixamos de o fazer, conservando, entretanto, es negativos no arquivo da Secção. 


\section{2 - Métodos}

Em nossos estudos, a capacidade geral de combinação da variedade foi testada no início dos trabalhos, polinizando-se plantas S0 dos diversos tipos Catêtos entre si e com o Catêto P-104, que, então, fôra adotado como padrão. Incluimos, na presente publicação, apenas 3 variedades das que se mostrarara mais promissoras.

A partir de 1945, o material foi mantido por dois processos:

a) por autofecundação, a fim de se obter linhas homogêneas. Na seleção das linhas autofecundadas não consideramos a produção, mas sòmente outros característicos agronômicos desejáveis nessa gramínea.

b) O segundo processo, por nós denominado "entre-linhas", consistiu na polinização controlada das plantas S0 entre si. Nêste caso, além dos caracteres de planta e espiga, levamos ainda em consideração a produção.

Como vemos, êsse processo nada mais é que um método para manter e melhorar a variedade original e obter, posteriormente, pela mistura dos cruzamentos controlados entre as linhas, uma variedade sintética.

Como já dissemos no início, o nosso objetivo é testar a capacidade geral de combinação das linhagens autofecundadas. O processo por nós utilizado foi, em princípio, o de cruzamento linha $\mathrm{x}$ variedade.

Os "top-crosses" foram obtidos polinizando-se as plantas provenientes de linhas com 2 a 5 autofecundações, com uma mistura de polem de 15 plantas escolhidas dentro do grupo, "entre-linhas". Não nos foi possível obter os cruzamentos das linhas com a variedade que deu origem às famílias autofecundadas, pois os nossos trabalhos foram iniciados com um número relativamente pequeno de espigas. Por isso, tornou-se necessário o processo "entre-linhas", pelo qual foi obtido uma variedade sintética provavelmente superior à variedade original não selecionada.

Incluimos, nêste trabalho, os dados referentes à altura da planta e da espiga de 15 representantes de cada “top-cross". $\mathrm{Na}$ análise da produção foram consideradas tôdas as plantas de cada cruzamento linha $\mathrm{x}$ variedade, isto é 26 ; foram medidas $\mathrm{e}$ pesadas em separado as primeiras, segundas, e às vêzes as terceiras espigas.

Como base de comparação dos "top-crosses" de Marília e Ipanema, usamos, em primeiro lugar, a produção média de cada grupo. Além disso, achamos interessante utilizar outros padrões de tipos comerciais. Assim, no caso dos catêtos de nossa 
região, isto é, $\mathrm{P}-139$ e $\mathrm{P}-140$, adotamos como padrão comercial o híbrido duplo de Campinas IA-3531.

A comparação do Quarentão não foi possível ser feita com a variedade sintética correspondente, pois esta portou-se muito mal, isto é, inferior à média dos "top-crosses" dêsse grupo. Assim sendo, a comparação dos cruzamentos linha $\mathrm{x}$ variedade foi feita com a média de produção dos "top-crosses".

O plano experimental consistiu na utilização de blocos ao acaso, com duas repetições. Incluimos, ainda, controles intercalados entre as linhas, que nos serviram como indicadores da homogeneidade do terreno: no caso dos Catêtos P-139 e P-140 o híbrido duplo de Campinas, e, no do Quarentão, a variedade sintética correspondente.

Os detalhes do plano experimental, assim como a análise do terreno, foram relatodos pelo Prof. F. G. Brieger nas duas últimas reuniões de estatísticas realizadas em Campinas e Piracicaba, motivo pelo qual deixamos de fazer referência, assinalando, apenas, que o terreno se mostrou razoavelmente uniforme e o experimento, homogêneo.

Os “top-crosses" de Quarentão foram plantados em terreno da Seção de Genética, terreno êste que há 5 anos vem sendo cultivado com milho; às vêzes após a colheita, fazia-se uma rotação com Crotolaria juncea.

Os Catêtos de Marília e Ipanema foram plantados em terra roxa profunda, da Fazenda S. Pedro, gentilmente cedida pelo Sr. Lino Morganti. No ano anterior, essa área havia sido cultivada com Crotolaria juncea.

De modo geral, podemos dizer que os terrenos da Seção de Genética são menos férteis que os da Fazenda S. Pedro, da Usina Monte Alegre.

Como adubo foram utilizados 350 quilos de superfosfato por hectare, embora os técnicos do Instituto Agronômico aconselhem de 160 a 400 quilos por hectare, conforme o solo seja mais ou menos fértil. O plantio foi feito em época apropriada e as condições climatéricas decorreram normalmente.

\section{5 - ANALISE ESTATISTICA}

\section{1 - Resultados experimentais de "top-crosses" coin duas variedades de Catêto}

Como já nos referimos, não abordaremos aquí a parte estatística do plano experimental; entretanto, para poder avaliar os resultados genéticos de grande importância para nós, dare- 
mos em primeiro lugar os valores das médias gerais, êrros e coeficientes de variação, que são os seguintes:

Produção (kg pnr $10 \mathrm{~m} 2$ ), quatro parcelas

\begin{tabular}{|c|c|c|c|}
\hline & Média & Erro & Coof. Var. \\
\hline $\begin{array}{l}\text { "Top-cross" Marília } \\
\text { “Top-cross" Ipanema } \\
\text { Híbrido duplo Campinas }\end{array}$ & $\begin{array}{l}6,23 \\
5,09 \\
6,61\end{array}$ & $\begin{array}{l}0,19 \\
0,28 \\
0,42\end{array}$ & $\begin{array}{l}3,1 \% \\
5,5 \% \\
6,3 \%\end{array}$ \\
\hline \multicolumn{4}{|c|}{ Altura das plantas $(\mathrm{cm}) 30$ plantas } \\
\hline $\begin{array}{l}\text { “Top-cross” Marília } \\
\text { “Top-cross” Ipanema } \\
\text { Híbrido duplo Campinas }\end{array}$ & $\begin{array}{l}284 \\
251 \\
271\end{array}$ & $\begin{array}{l}17.7 \\
18.5 \\
20,6\end{array}$ & $\begin{array}{l}6,2 \% \\
7.4 \% \\
7.6 \%\end{array}$ \\
\hline \multicolumn{4}{|c|}{ Altura da Espiga $(\mathrm{cm}) 30$ plantas } \\
\hline $\begin{array}{l}\text { “Top-cross" Marília } \\
\text { "Top-cross" Ipanema } \\
\text { Híbrido duplo Campinas }\end{array}$ & $\begin{array}{l}181 \\
149 \\
169\end{array}$ & $\begin{array}{l}17,1 \\
16,8 \\
21,9\end{array}$ & $\begin{array}{r}9,4 \% \\
11,3 \% \\
12,9 \%\end{array}$ \\
\hline
\end{tabular}

Pêso médio (gr) das espigas

$\begin{array}{lccc} & \text { 1 }^{\text {a. Esp. }} & \text { 2 }^{\text {a. Esp. }} & \begin{array}{c}\text { \% de 2 } \\ \text { espigas }\end{array} \\ \text { “Top-cross" Marília } & 146 & 122 & 85 \% \\ \text { "Top-cross" Ipanema } & 142 & 101 & 82 \% \\ \text { Híbrido duplo Campinas } & 144 & 124 & \mathbf{9 4 \%}\end{array}$

Verificamos pela tabela acima, que os coeficientes de variação são todos muito pequenos, isto em vista de se tratar de experimentos de campo, o que permite uma análise estatística das médias dos diferentes top-crosses e dos caracteres em estudo.

\section{2 - Estudo da variação genética}

Os resultados a serem discutidos estão resumidos nas tabelas de 1 a 3 para os "top-crosses" Marília, e de 4 a 6, para os de Ipanema. Estas tabelas seguem em grande parte, pelo menos, a mesma organização : encontramos a esquerda, 4 colunas duplas, designadas por S1, S2, S3 e S4. Nelas assinalamos os números que as respectivas linhagens autofecundadas possuem nos nossos protocólos, e assim podemos, fàcilmente, verificar seu "pedigree". Por exemplo, na tabela 1, os trabalhos com Marília foram iniciados com duas plantas autofecundadas que de- 
ram origem a duas famílias $\mathrm{S} 1$, que receberam os números $3 \mathrm{~A}$ e 2A. Três indivíduos da primeira geração foram novamente autofecundados, dando as famílias S2, que receberam os números: $742,743,745$. Na família 743 novas autofecundações foram levadas a efeito em 3 indivíduos, resultando, daí, as famílias S3 - 1160, 1161 e 1162. Na família 1161, apenas uma planta foi autofecundada dando a família $\mathrm{S} 4$, com o número 308 , enquanto que as duas outras famílias de S3 por autofecundação de dois indivíduos de cada linhagem originaram as famílias S4 com número 305 e 306, e 309 e 310, respectivamente. Finalmente, um indivíduo de cada família da geração S4, isto é, com 4 autofecundações, foi polinizado com uma mistura de polem de 15 plantas de um sintético da mesma variedade e, assim, foi obtido um "top-cross" para cada família de S4.

Para completar o histórico, devemos acrescentar que, o número de indivíduos autofecundados, em cada geração era de cêrca de 5 a 10, pois efetuamos rigorosa seleção de plantas, e espigas, após a colheita. Queremos frizar ainda, que o número de famílias autofecundadas, de cada geração, era bem maior do que o indicado na tabela, pois foram após a seleção dos caracteres em geral, desprezadas famílias inteiras, por serem indesejáveis.

Ao lado de cada número de família e geração, temos sempre o valor de u'a média. A coluna $\mathrm{S} 4$ se refere às médias de cada top-cross. Nas gerações anteriores consta sempre a média do conjunto de top-crosses com "pedigree" comum; assim por exemplo, a média na tabela 1, ao lado da família 1160, da geração S3, é obtida tirando-se as médias das duas famílias, 305 e 306 , da geração $S 4$.

Nas tabelas referentes à altura da planta e espiga, temos ainda mais duas colunas : na penúltima, aparecem os êrros-padrão calculados sôbre 30 plantas de cada "top-cross"; na última, figuram os quocientes teta dêsses êrros individuais, divididos pelos êrros residuais que constam da tabela já referida.

Nas tabelas 3 e 6 , que apresentam os dados referentes à produção numa área de $10 \mathrm{~m} 2$, nas últimas três colunas à direita, constam ainda os seguintes dados: pêsos médios das primeiras e das segundas espigas de cada "top-cross" e percentagem de plantas com duas espigas.

Em alguns "top-crosses", houve de fato, a produção de unla 3a. espiga, mas como êstes casos foram raros, pouca influência tiveram sôbre a produção total, tornando-se assim desnecessária a apresentação dêsses dados. 
5.3 - Análise da variação : alturas de planta e espiga; produção

Referimo-nos anteriormente ao momento em que se deve testar as linhas durante o processo de homogenização.

Uma antecinação dêsse teste sempre determina uma grande ecunomia de material, trabalho e despesas, mas uma análise prematura poderá ser de pouco valor, se o material for demasiadamente heterozigoto nessa ocasião.

SPRAGUE e BRYAN (33), estudando a segregação para a produção e a resistência ao acamamento, pelo processo linha $\mathrm{x}$ variedade, em família S4, verificaram que as mesmas ainda segregavam para essas características nessa geração.

JENKINS (36), verificou que a segregação em gerações sucessivamente autofecundadas era muito grande nas primeiras gerações, decrescendo à media que o processo de homogenização continuava.

A comparação em nosso material, das médias consecutivas, grupadas de acôrdo com o seu pedigree nas gerações S3, S2 e $\mathrm{S} 1$, tornam evidente, que houve bastante segregação nessas gerações, o que está de acôrdo com os resultados de JENKINS.

No caso dos "top-crosses" de Marilha, não pode haver dúvida de que as plantas iniciais $\mathrm{S} 0$ eram genéticamente diferen-. tes, pois seus descendentes deram médias de altura de planta e espiga significativamente diferentes.

Nas tabelas 1, 2, 4 e 5, os valores de teta são geralmente bastante pequenos e o fato de alguns dêles serem superiores a 1,30 , não é suficiente para indicar que houve uma segregação genética em algumas famílias de S4.

Uma análise das diferenças consecutivas para os mesmos carateres, em parte significantes (fora do limite de $1 \%$ o de probabilidade), prova que houve bastante segregação entre os indivíduos da primeira até a terceira autofecundação, inclusive.

Para a variedade comercial Ipanema, embora não havendo grande diferença entre as plantas S0, o fato de numerosas diferenças consecutivas de S2 a S4, serem ou significante ou duvidosas, nos leva também a conclusão de que houve bastante segregação genética da primeira à segunda gerações autefecundadas, inclusive.

Passamos agora a discutir a produção das duas variedades anteriormente referidas (tabelas 3 e 6). Evidentemente, não houve, nem em Marília nem em Ipanema diferenças entre as plantas S0 escolhidas, tomando-se por base suas capacidades de cumbinação, pois não constatamos diferenças significantes consecutivas entre as famílias S1. Porém, a segregação das 
plantas S1 a S3 é evidenciada pelo aparecimento de diferenças estatisticamente duvidosas ou significantes entre as médias consecutivas de S2 a S4, referentes a produção.

Tais dados permitem, ainda, discutir a época em que se deve testar as linhagens quanto à capacidade geral de combinaçăo.

Uma avaliação prematura da capacidade geral de combinação poderia causar perda de material de inestimável valor.

Para discutirmos êsse ponto, devemos antes de mais nada, fazer uma comparação das médias de cada "top-cross", com a média geral de cada grupo.

As médias da coluna S4, que não são acompanhadas de qualquer sinal, não diferem estatisticamente da média geral, Aquelas acompanhadas de um sinal $(+)$ ou $(-)$ indicam que a diferença entre a média individual e a geral é maior que o limite de $5 \%$ de probabilidade; dois sinais $(++)$ ou $(--)$ indicam que foi ultrapassado o limite de $5 \%$ e, finalrnente 3 sinais correspondem ao limite de $1 \%$ o de probabilidade.

Entre os "top-crosses" de Marília (tabela 3) poderiamos escolher a família 739 (S2) que deu origem a quatro linhagens em S4, tôdas com cruzamento linha $x$ variedade, bastante produtivos,pois podemos considerar o "top-cross" de número 301 (S4) como, provàvelmente, muito bom, pela seguinte razão: produção total baixa, naturalmente em consequência de má germinação, apresentando um stand muito incompleto; porém a produção por espiga e a percentagem de plantas com duas (2) espigas, foram bôas. De outro lado, os cinco "top-crosses" derivados da família 743 (S2), apresentaram produções inferiores a média geral. Assim, pelo menos nêstes dois casos, poderiamos, supor que um teste da capacidade de combinação das plantas S1, que deram as famílias S2 por autofecundação, teria talvez, permitido eliminar o indivíduo que deu origem à descêndencia 734 (S4), auxiliando assim a escolha de mais plantas que prometessem melhores descendentes.

Também nos cruzamentos linha $\mathrm{x}$ variedade de Ipanema, (tabela 6), poderiamos notar certos agrupamentos; assim, os 5 "top-crosses" derivados da família 776 (S2) apresentanı as primeiras espigas muito bôas; a produção total, em parte, varia de média até muito bôa em consequência das segundas espigas não serem muito pesadas e também devido ao fato da tendência de plantas com 2 espigas ser relativamente pequena. Porém, na inaioria dos casos, a segregação é bastante pronunciada em gerações mais avançadas que em $\mathrm{S} 1$, o que reduziria a eficiência de um teste prematuro, caso fosse realizado. 
Os dados referentes ao Marília constam das tabelas 1, 2, 3 e 10. Por essas tabelas verificamos que três "top-crosses" (300, 303 e 287) se mostram talvez mais produtivos e, cinco outros, muito provàvelmente superiores em produções aos demais.

A maioria dos cruzamentos linha $\mathrm{x}$ variedade se distingue, ou pela alta percentagem de segundas espigas ou pelo elevado pêso das mesmas.

Notamos ainda que nove outros "top-crosses" apresentam de modo geral, porte mais baixo, relativamente a altura da planta e da espiga. Entre êstes últimos caracteres existe uma correlação linear positiva, sendo que os coeficientes correspondentes de BRAVAIS que figuram no quadro abaixo, são estatisticamente significantes.

Produção x Altura da Planta Produção x Altura da Espiga Alt. da Planta x Alt. do Espiga

$\begin{array}{cc}\begin{array}{c}\text { Coeficiente de } \\ \text { Marilia }\end{array} & \begin{array}{c}\text { Ipanema } \\ +0,41\end{array} \\ +0,48 & +0,42 \\ +0,38 & +0,41 \\ +0,89 & +0,71\end{array}$

Se compararmos os resultados da seleção, de acôrdo com os dois critérios, isto é, produção e altura de planta, podemos constatar o seguinte : as plantas de bôa produção geralmente apresentam porte alto ou médio, e as de porte baixo possuem menor produção.

Há evidentemente uma tendência não muito forte para a correlação positiva entre os dois caracteres mencionados, pois muitas famílias de porte alto apresentam produção média.

Há evidentemente uma tendência não muito forte para a correlação positiva entre os dois caracteres mencionados, pois muitas famílias de porte alto apresentam produção média.

Os dados referentes aos "top-crosses" de Ipanema estão contidos nas tabelas 4,5 e 6 .

Notamos pela análise das tabelas acima mencionadas que cinco top-crosses são mais produtivos que os demais, e também que cinco outros apresentam menor porte.

De maneira geral, podemos verificar que porte baixo e alta produção são caracteres opostos na seleção, e que os gens responsáveis pelo vigor vegetativo e produção devem ser em grande parte os mesmos.

Posteriormente comparamos os diversos "top-crosses" com o híbrido duplo do Instituto Agronômico de Campinas, IA-3531.

Os "top-crosses" de Ipanema apresentaram produção média individual e geral inferiores a do híbrido duplo acima referido, 
sendo porém, o seu porte mais baixo e, consequentemente, com relação a êsse carater, mais vantajoso.

Os "top-crosses" de Marília são em parte tão produtivos quanto o híbrido de Campinas, sendo alguns superiores. Entretanto, devemos acrescentar que o seu porte é geralmente mais elevado que o do híbrido duplo IA-3531.

Parte das sementes das melhores linhagens de Marília testadas pelo método de cruzamento linha $\mathrm{x}$ variedade foram cedidas êste ano ao Dr. Glauco Pinto Viégas, do Instituto Agronômico de Campinas.

Recebemos também daquêle Instituto algumas linhagens autofecundadas que foram incorporadas à coleção da Secção de Genética.

O aproveitamento do material, no futuro, dependerá do programa de melhoramento. Evidentemente, as linhagens de Ipanema não oferecem muitas vantagens na obtenção de variedades sintéticas, para as quais o Marília é o mais indicado.

De fato, a Seção de Genética, já possue um sintético que se aproxima bastante em produção ao híbrido duplo.

Para um programa de híbridos simples ou duplos, parecenos mais indicado, usar os dois grupos de linhagens, devido a diversidade Genética do matrial (13), (22), (23) e (24), pois da combinação de híbrido simples de Marília e Ipanema, podemos esperar um híbrido duplo de boa produção e de menor porte.

E' nossa intenção incluir aos nossos futuros trabalhos de melhoramento as linhagens de Catêto, cedidas pelo Instituto Agronômico de Campinas.

\section{4 - Resultados experimentais de "top-crosses" com Quarentão}

Os estudos com os "top-crosses" desta variedade foram executados em terreno da Secção de Genética, bastante exgotado, o que prejudicou sobremaneira as plantas, quer quanto a altura quer quanto a produção. Entretanto, em comparação com as linhagens autofecundadas êles se mostraram bastante superiores; mesmo quando comparados com a variedade sintética provisória usada como testemunha, comportaram-se melhor.

Em primeiro lugar, daremos os valores médios para o conjunto dos 27 "top-crosses" obtidos de duas variedades de Quarentão, denominadas "Estanzuela" e "Klein", de acôrdo com a sua origem. 


\begin{tabular}{|c|c|c|c|}
\hline & Média & Erro & Coef. Var. \\
\hline Produção média em kg por & & 096 & $110 \%$ \\
\hline Pêso médio da 1a. espiga & $\begin{array}{r}r, 10 \\
84\end{array}$ & - & - \\
\hline Pêso média da 2a. espiga & 54 & - & - \\
\hline$\%$ de plantas de 2 espigas & $50 \%$ & $\overline{10}$ & $-\pi$ \\
\hline $\begin{array}{l}\text { Alturà da planta } \\
\text { Altura da espiga }\end{array}$ & $\begin{array}{r}131 \\
42\end{array}$ & $\begin{array}{l}15 \\
10\end{array}$ & $\begin{array}{l}11.4 \% \\
23,8 \%\end{array}$ \\
\hline
\end{tabular}

Como os coeficientes de variação são razoavelmente pequenos, exceção feita ao coeficiente 23,8 , podemos proceder a análise dos dados individuais dos 27 "top-crosses".

\section{5 - Segregação}

Os dados constantes das tabelas 7 a 9 foram organizados do mesmo modo que os das tabelas de 1 a 6 , apenas com a seguinte diferença: no caso em discussão, não foram feitos os "topcrosses" só com indivíduos autofecundados da 4a. geração (S4), mas, conforme o caso, já nas gerações S2 ou S3, o que causou pequenas alterações na confecção das tabelas.

Como se pode facilmente verificar, os resultados com esta variedade de milho, são semelhantes aos casos anteriores, havendo pouca diferença genética entre os indivíduos S0 que originaram as famílias da primeira autofecundação (S1); houve, entretanto, grande segregação para todos os caracteres estudados nos indivíduos das gerações S1 a S3.

Os dados não demonstram de modo convicente a existência de uma segregação em S4, apezar da variação de alguns dos êrros fornecer uma indicação nêste sentido.

\section{6 - Seleção}

Como base de comparação, usaremos unicamente as médias do conjunto dos "top-crosses".

Os resultados dessa seleção constam do quadro seguinte :

Com relação à produção, 3 "top-crosses" de quarentão certamente, e mais dois possivelmente, são superiores aos demais. Uma boa parte dêles se distingue também pelo porte mais alto, seja com relação à altura da planta, seja quanto à posição de espiga.

Levando-se em conta o porte das plantas, acrescentaremus ainda cinco "top-crosses", $(2,4,13,18$ e 19) apesar da sua pr(cdução ser média ou mesmo inferior. 


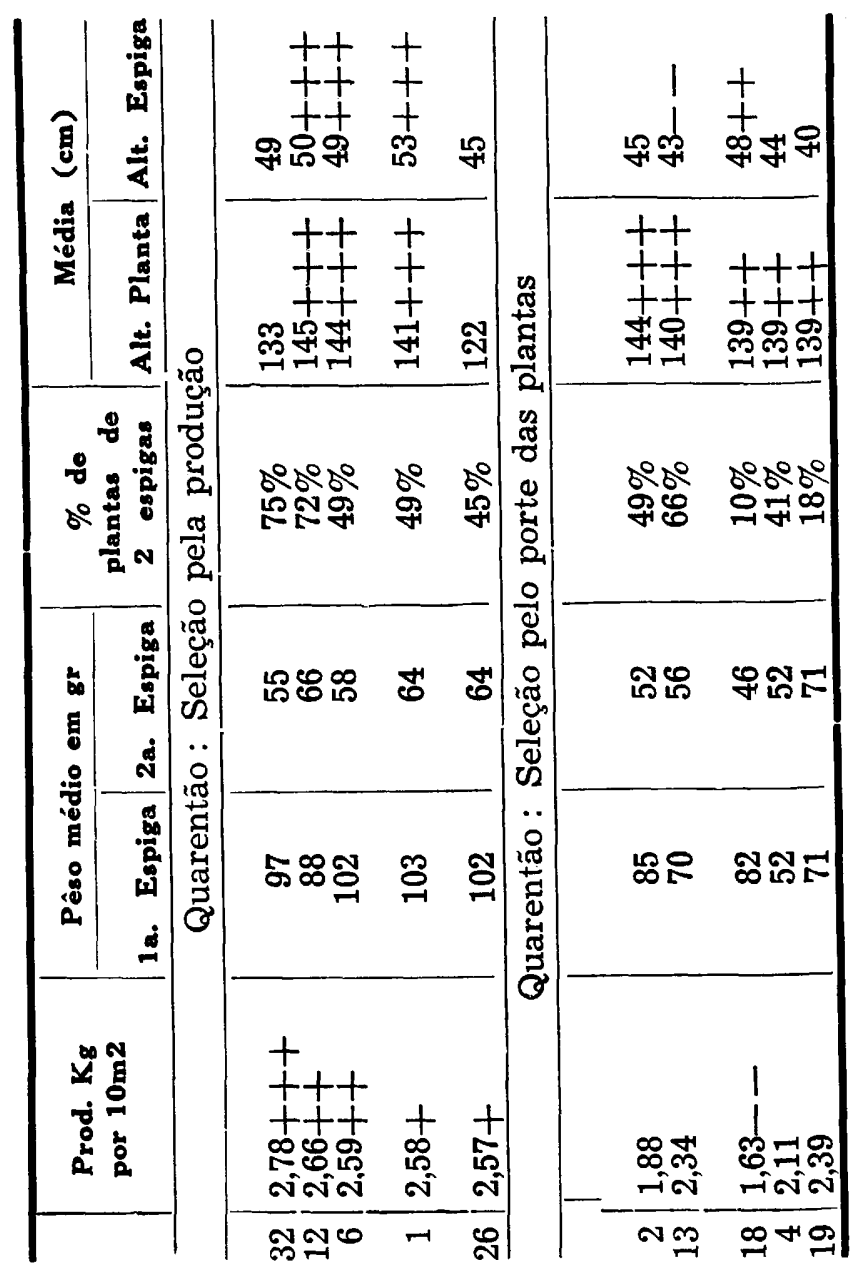

No primeiro caso, da seleção pela produção, observamos o mesmo que já foi constatado para as variedades Marília e Ipanema, isto é, parece coincidir o vigor híbrido máximo para todos os caracteres estudados, tanto dos orgãos vegetativos com 0 dos reprodutivos.

O segundo grupo de dados, seleção pela altura, indica, porém que a correlação entre o vigor híbrido vegetativo e reprodutivo não é muito forte no Quarentão.

Se quizermos fazer ainda uma comparação dos resultados obtidos com os das demais variedades de Catêto, aos quais pertencem tanto o Marília como Ipanema, bem como o híbrido du- 
plo de Campinas, devemos lembrar que se trata de tipos bastante diferentes e de utilidades as mais diversas.

O Quarentão é um típo prococe, que pode ser empregado entre nós, apenas em condições muito especiais, como por exemplo, quando as condições adversas impedem o plantio de milho comum em época normal, forçando assim o lavrador a recorrer a um plantio tardio.

Convém, entretanto, frisar que a maior precocidade dêsses tipos duros da bacia do Plata é correlacionada com menor altura de planta e produção, quando comparados com as nossas variedades comuns.

Queremos ainda lembrar que o Quarentão cultivado na Secção de Genética, apresenta grãos bem menores que os Catêtos comuns e sua coloração alaranjada é bem mais intensa.

Assim, o Quarentão entre nós, evidentemente, destina-se a usos especiais como alimentação de aves, etc.

No que diz respeito à menor produção por parcela e por planta, queremos também lembrar que no plantio normal, êsse defeito é em grande parte compensado por uma plantação mais densa, o que aumenta a produção por área.

\section{RESUMO E CONCLUSÕES}

1. Sempre que trabalhamos com milho ou outra planta qualquer, devemos antes de mais nada, conhecer perfeitamente o material que servirá de base aos nossos estudos, assim como as exigências do mercado e da lavoura.

2. Se vamos produzir milho para indústria ou exportação, teremos que lançar mãos dos tipos duros alaranjados, conhecidos pela denominação genética de Catêtos. Se, por outro lado, o objeto principal é a alimentação dos animais domésticos, lançaremos mãos do tipo Dente mole.

3. Atualmente, cêrca de dois terços da área paulista cultivada com essas importante gramínea o são com Dente, ao passo que antigamente se emprestava maior importância ao Catêto.

4. Uma vez cientes das exigências do mercado e da lavoura, devemos procurar conhecer a distribuição geográfica do material básico de nossos trabalhos de melhoramento, pois qualquer método fitotécnico inclui, sempre, a necessidade de se procurarem novas fontes de variação, afim de que sejam obtidos novos caracteres agronômicos desejáveis. Segundo F. Brieger os tipos duros alaranjados apresentam a seguinte distribuição geográfica : a) da bácia do Plata até mais ou menos o Rio de 
Janeiro, b) mais ao norte, isto é, desde a fóz do Amazonas até o mar das Caraibas. Entre essas duas áreas de distribuição, o Catêto não é encontrado puro, mas mesclado com milho Dente norte-americano ou indígena.

5. Escolhidos o tipo padão e a matéria prima, devemos elaborar o plano de melhoramento à ser seguido.

As plantas escolhidas são à seguir submetidas a uma série de autofecundações, cuja finalidade é obter linhagens puras. Como êsse processo de homogenização determina uma perda de vigor e produção, necessário se torna, para o restabelecimento do vigor e produtividade, recorrermos a cruzamento entre as linhagens autofecundadas. Entretanto, antes de efetuarmos tais cruzamentos, devemos procurar conhecer a produção das linhagens quando combinadas em híbridos.

A previsão do comportamento das linhagens nos futuros híbridos, poderá ser avaliada testando-se as suas capacidades geral e específica de combinação.

6. A avaliação da capacidade geral de combinação é geralmente feita pelo cruzamento linha $x$ variedade, enquanto que, a capacidade específica de combinação o é pelo comportamento das melhores linhagens em todos os possíveis híbridos simples com elas obtidas.

7. Duas correntes discutem ainda hoje o momento em que se deve avaliar a capacidade geral de combinação, se no início dos trabalhos, com o auxílio do "early testing" ou mais tardiamente, empregando o "late testing".

Essa questão da prova da capacidade geral de combinação, parece em parte, depender das condições de trabalho e inclinação pessoal do pesquisador, assim como do material útilizado.

8. Na presente Publicação utilizamos os milhos duros alaranjados denominados Catêto Marília, Ipanema e Quarentão. Os dois primeiros são originários dos municípios que lhes emprestam o nome, enquanto que o último é proveniente do Uruguai. Ėsses três tipos apresentam diferenças não só quanto a precocidade, altura de planta e espiga, mas também quanto a coloração e tamanho dos grãos.

9. Em nossas experimentações a capacidade geral de combinação foi avaliada pelo método de cruzamento linha $\mathrm{x}$ variedade.

Deixamos de abordar os problemas referentes à capacidade específica de combinação e, vigor de híbrido (heterosis), pois trataremos dos mesmos em um futuro trabalho.

10. Considerando que os coeficientes de variação em tôdos os experimentos apresentados, são menores, pelo menos que 20\%, 
e em grande parte menores que $10 \%$, é perfeitamente lícito submeter os dados à uma análise detalhada.

11. Os très grupos de "top-crosses" das variedades Marília e Ipanema do Catêto comum, e das raças Estanzuela e Klein da variedade Quarentão, mostram a existência de uma segregação genética para gens responsáveis pela capacidade de combinação, com referência à três caracteres: produção, altura média de planta e altura média de espiga.

12. Sómente em alguns casos houve diferenças genéticas entre os indivíduos de geração S0 que sofreram a primeira autofecundação.

13. Há uma segregação bastante pronúnciada nos individuos autofecundados das gerações S1 a S3.

14. Os dados apresentados não demonstram que a segregação contínua ainda na geração $\mathrm{S4}$, mas também não mostram de um modo decisivo o contrário.

15. Na seleção entre os "top-crosses", tornou-se evidente não ser possível relacionar os três caracteres em estudo, isto é, alturas de planta e espiga e produção, independentemente. Há sempre uma correlação linear positiva entre a altura de planta e da espiga, no material estudado; Brieger e Graner (14), também observaram a mesma causa em milho Sta. Rosa.

A correlação positiva entre altura da planta e altura de espiga, e a produção por parcela, é relativamente pequena, demodo que nem sempre as plantas mais produtivas são ao mesmo tempo aquelas que possuem um maior vigor vegetativo. Todavia, exclue-se pràticamente a combinação mais desejável aos rıossos Catêtos, ou seja, alta produção e porte baixo.

16. A interpretação genética dos resultados relatados em 15 deve ser a seguinte: a quase totalidade dos gens que controlam a altura da planta nos top-crosses, são identicos áqueles que determinam a altura da espiga.

17. A seleção dos top-crosses da variedade Marília, tomando como base a média dos cruzamentos linha $\mathrm{x}$ variedade, demonstrou que cinco cruzamentos são estatisticamente superiores à média geral, com produção entre 7,1 e $7,8 \mathrm{Kg}$ por $10 \mathrm{~m} 2$, indicando, assim, que as respectivas linhagens $\mathrm{S} 4$ possuem uma maior capacidade de combinação, sendo ainda 3 outros, possivelmente melhores.

Comparando os "top-crosses", com o híbrido duplo de Campinas, cuja produção foi de $6,6 \mathrm{Kg}$ por $10 \mathrm{~m} 2$, constatou-se que alguns igualaram o referido híbrido e, pelo menos dois, tomando como base o limite de probabilidade rigoroso de $1 \%$, são superiores em produção, isto é 7,5 e $7,8 \mathrm{Kg}$ por $10 \mathrm{~m} 2$, sendo entretanto, de porte um pouco mais alto. 
18. Relativamente a variedade Ipanema notamos que cinco cruzamentos linha $\mathrm{x}$ variedade apresentam produção supe. riores aos demais. (ver tabela 6) Em comparação com o híbrido duplo de Campinas, todos são inferiores em produção, porém, se destacou pelo seu menor porte.

19. Do que foi exposto em 17 a 18, e levando-se ainda em consideração a diversidade genética do material, seria interessante confecionar híbridos com linhagens de uma mesma variedade; entre as duas variedades (Marília e Ipanema); e finalmente, o que seria mais aconselhável entre linhagens de Marília e as melhores linhagens que entram na composição do híbrido duplo de Campinas I. A. 3531.

20. A análise dos "top-crosses" do Quarentão evidênciou que 5 deles são superiores aos demais em produção, variando esta entre 2,6 e $2,8 \mathrm{Kg}$ por $10 \mathrm{~m} 2$. Com relação a esta variedade queremos ainda lembrar que se trata de um tipo especial, de precocidade muito pronúnciada, entre nós, e que não pode ser comparado de qualquer forma com o catêto comum.

\section{AGRADECIMENTOS}

O material básico deste nosso trabalho proveio da coleção de milho comercial da Secção de Genética, da Escola Superior de Agricultura "Luiz de Queiroz".

Todos os trabalhos de laboratórios e parte dos de campo foram levados a efeito na mesma Secção. Por êsses motivos e por outras facilidades postas à nossa disposição, bem como pela orientação dada no decorrer dos trabalhos e na preparação do manúscrito, queremos aqui deixar consignados nossos sinceros agradecimentos ao Prof. F. G. Brieger, Chefe da referida Secção.

Parte dos trabalhos experimentais foram executados em terrenos da Fazenda São Pedro, da Usina Monte Alegre, gentilmente cedido pelo sr. Lino Morganti, à quem consignamos também nossos agradecimentos.

Queremos ainda agradecer ao eng. agr. Eno Cardoso Miranda, que nos proporcionou inúmeras facilidades no decorrer de nossas experiências naquela fazenda.

Ao docente livre Dr. José Theophilo do Amaral Gurgel, pelas valiósas sugestões e críticas apresentadas na elaboração do manúscrito, queremos também tornar público o nosso agradecimento.

Ao docente livre Dr. Zilkar Cavalcante Maranhão, nossc particular amigo que muito nos auxiliou na preparação das ta- 
bélas, bem como desenhando o mapa que ilustra o presente trabalho, o nosso muito obrigado.

Queremos, ainda, consignar nossos agradecimentos ao Prof. Silvio de Aguiar Souza, pela revisão gramatical do manúscrito, da primeira parte deste trabalho.

Como auxiliares dirétos estiveram à nossa disposição no decorrer da preparação deste trabalho os srs. Antonio Gosser, fiscal de campos; Adalberto Gorga e Oswaldo Peres, calculistas; José Penteado Maia e João Zandoval Neto, datilógrafos; assim como, José Broglio e Humberto Gorga Filho, todos funcionários da Secção de Genética, que mesmo fora do período regulamentar de trabalho, colaboraram de maneira eficiente na preparação deste trabalho. À êles o nosso sincero agradecimento.

\section{BIBLIOGRAFIA}

BRIEGER, F. G. (31) - Limites unilaterais e bilaterais na análise estatística. Sep. Rev. Bragantia 6: 479-545, 6 figs. 1946.

(1) - Origem e centros de domesticação do milho. II. Centros de domesticação. Melhoramento. Sep. Rev. Ciência e Cultura, vol. I, n. 4, p. 190-201. 1949.

(2) - A distribuição do milho indígena e comercial. La Primera Asamblea Latinoamericana de Fitogenetistas. Folleto Miscellanea n. 3, novembro. Secretaria de Agricultura y Ganaderia. Mexico. 1950.

DAVIS, R. L. (15) * - Report of the plant breeder. Puerto Rico. Agric. Exp. Sta. 1927.

(25) * - Maize crossing values in second generation lines. Jour. Agric. Res., vol. 48. 1934.

ECKHARDT, Robert C. \& Bryan, A. A. (24) - Effect of the method of combining the four inbred lines of a double cross of maize upon the yeld and variability of the resulting hybrid. Jour. Amer. Soc. Agron., vol. 32. 1940.

HAYES, $\dot{H} . \mathrm{K} .(7)^{*}$ - Present-day problems of corn breeding. Jour. Amer. Soc. Agron., vol. 18. 1926.

\& Immer, F. R. (9) - Metodos Fitotecnicos. Procedimientos Cientificos para mejorar las Plantas Cultivadas. (Traduzido do inglês por Antonio E. Marino). Buenos Aires. 1943.

lines of corn. Jour. Amer. Soc. Agron., vol. 31. 1939.

, Rinke, E. H. \& Tsiang, Y. S. (20) - Experimental study of convergent improvement and backcrossing in 
corn. Technical Bulletin 172. Univ. Minn. Agric. Exp. Sta. 1946.

JENKINS, M. T. (12)* - Correlation studies with inbred and crossbred strains of maize. Jour. Agric. Res., vol. 39. 1929.

- (26)* - The effect of inbreeding and of selection within inbred lines of maize upon the hybrids made after sucessive generations of selfing. Iowa State Col. Jour. Sci., vol. 9. 1935.

(30) - The segregation of genes offecting yeld of grain in maize. Jour. Amer. Soc. Agron., vol. 32. 1940.

—__ , \& Brunson, A. M. (17) - Methods of testing inbred lines of Golden Batam sweet corn. Jour. Amer. Soc. Agron., vol. 24. 1932.

JOHNSON, I. J., \& Hayes, H. K. (18) - The combining ability of inbred lines of Golden Bantam sweet corn. Jour. Amer. Soc. Agron., vol. 28. 1936.

(23) - The value in hybrid combinations of inbred lines of corn selected from single crosses by the pedigree method of breeding. Jour. Amer. Soc. Agron., vol. 32. 1940.

JONES, D. F. (14)* - The productiveness of single and double first generation corn hybrids. Jour. Amer. Soc. Agron., vol. 14. 1922.

\& Singleton, W. R. (21)* - The improvement of naturally cross-pollinated plants by selection in self-fertijized lines. II. The testing and utilization of inbred strains of corn. Conn. Agric. Exp. Sta. 1935.

JORGENSUN, L. \& Brewbaker, H. E. (11)* - A comparision of selfed lines of corn and first generation crosses between them. Jour. Amer. Soc. Agron., vol. 19. 1927.

KIESSELBACH, T. A. (4) - Corn Investigations. Res. Bull. Neb. Agric. Exp. Sta., n. 20. 1922.

KRUIFF, Paul de (3) - Os Vencedores da Fome (A história novelesca e heróica dos homens que afastaram para sempre o espectro da fome). Tradução de Lino Vallandro. Edição da Livraria do Globo, Porto Alegre. 1944.

LINDSTRON, E. W. (16)* - Prepotency of inbred sires cn commercial varieties of maize. Jour. Amer. Soc. Agron., vol. 23. 1931.

NILSON-Leissner, G. (10)* - Reltion of selfed strains of corn to F1 crosses between them. Jour. Amer. Soc. Agron., vol. 19. 1927.

RICHEY, F. D. (5) * - Effects of selection on the yeld of a cross between varieties of corn. Bull. U. S. Dept. Agric., n. 1209.1924 . 
\& Mayer, L. S. (6)* - The productiveness of suceessive generations of self-fertilized lines of corn and crosses between them. Bull. U. S. Dept. Agric., n. 1354. 1925.

SPRAGUE, G. F. (27) - An estimation of the number of topcrossed plants required for adequate representation of a corn variety. Jour. Amer. Soc. Agron., vol. 31. 1939.

(8) - The experimental basis for hybrid maize. Bctanical Review, pg. 101-120. 1946.

(29) - Early testing of inbred lines of corn. Jour. Amer. Soc. Agron., vol. 38. 1946.

\& Bryan, A. A. (28) - The segregation of genes affecting yeld prepotency, lodging, and disease resistance in F3 e F4 lines of corn. Jour. Amer. Soc. Agron., vol. 33. 1941. \& Tatum, L. A. (19) - General v. specific combining ability in single crosses of corn. Jour. Amer. Soc. Agron., vol. 34. 1942.

WU, Shao-Kwi (22) - The relationship between the origin of selfed lines of corn and their value in hybrid combination. Jour. Amer. Soc. Agron., vol. 31. 1939. 
TABELA 1

Marília - Altura da Planta

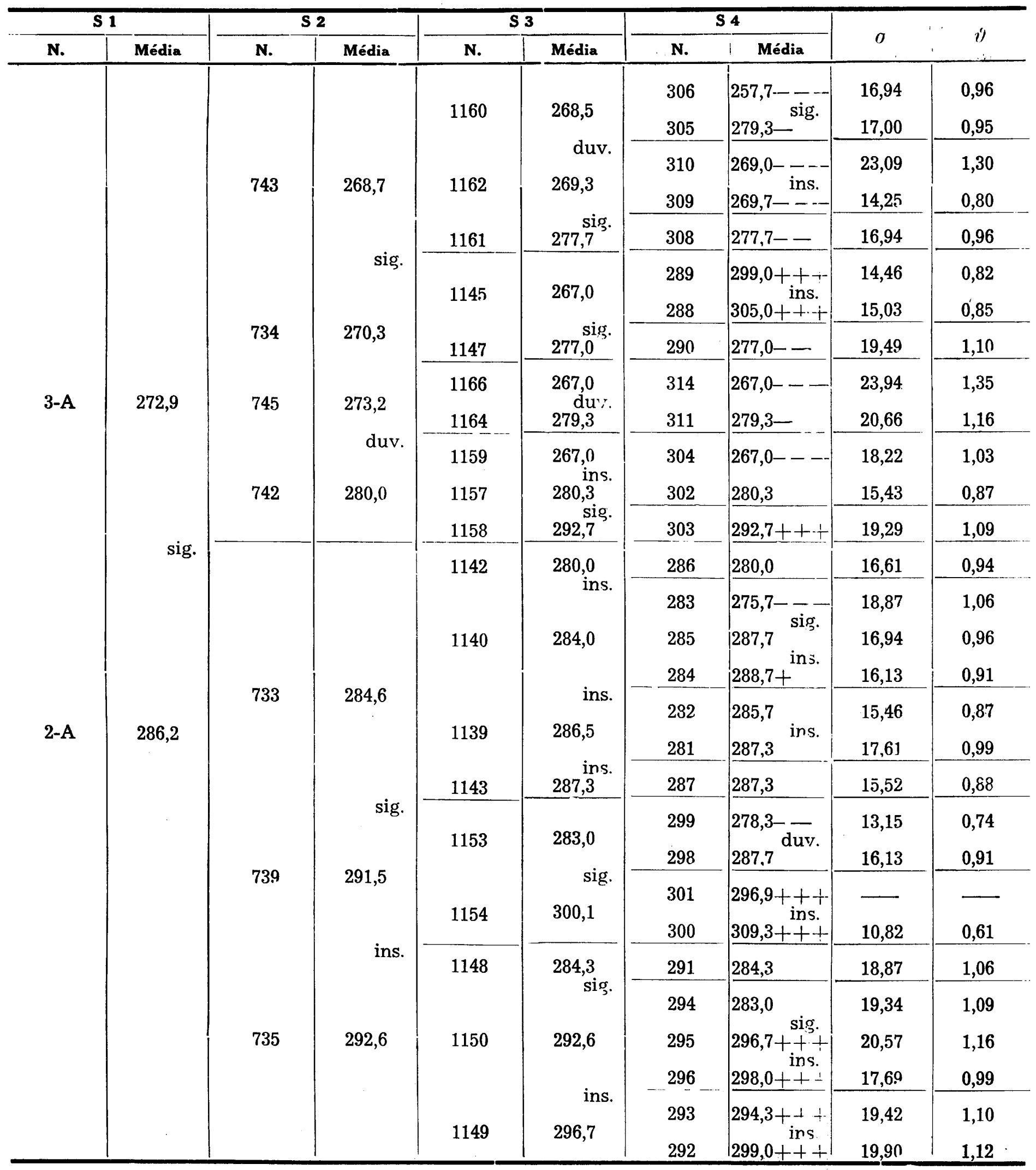


TABELA 2

Marília Altura da Espiga

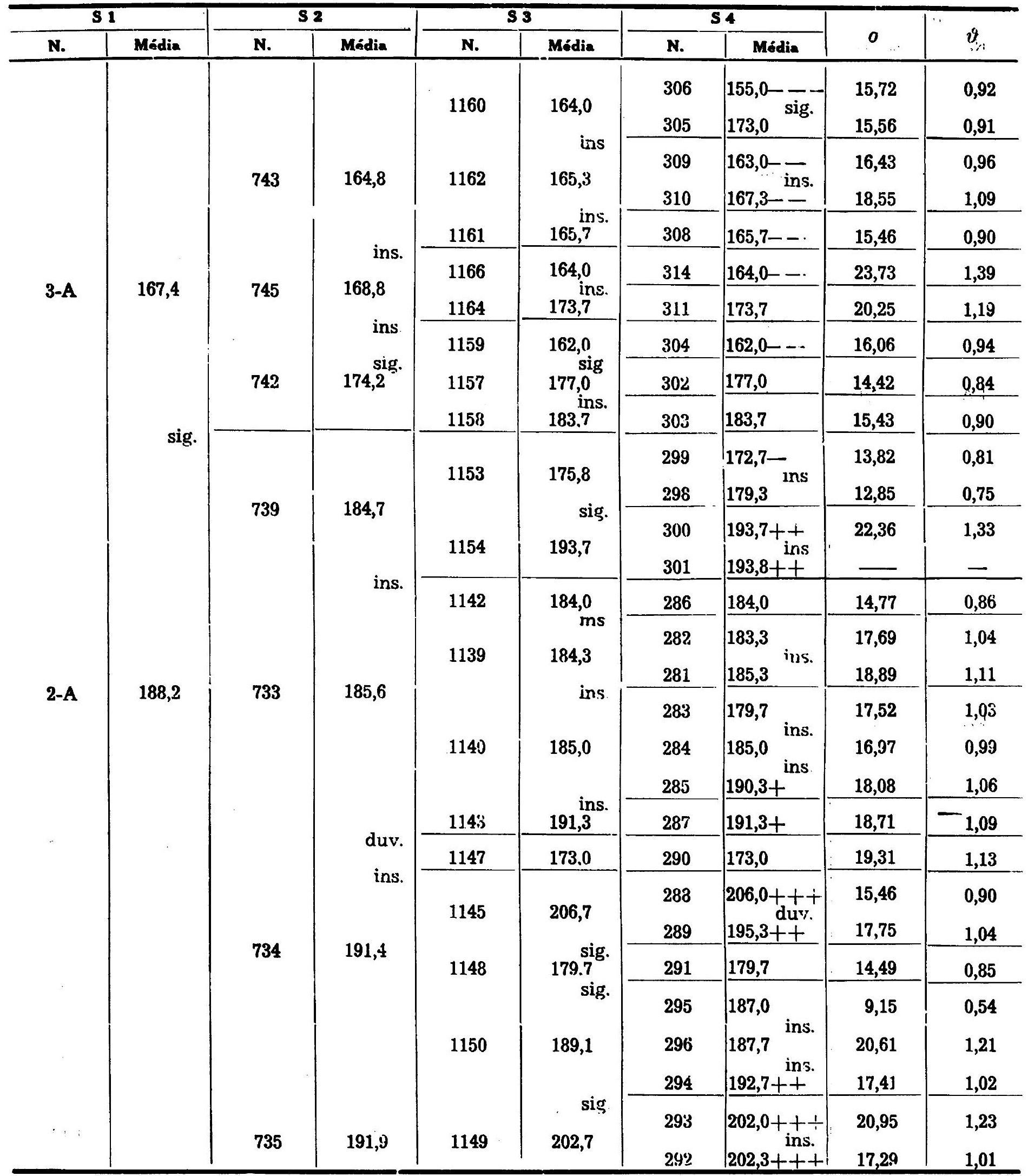


Marília - Produção

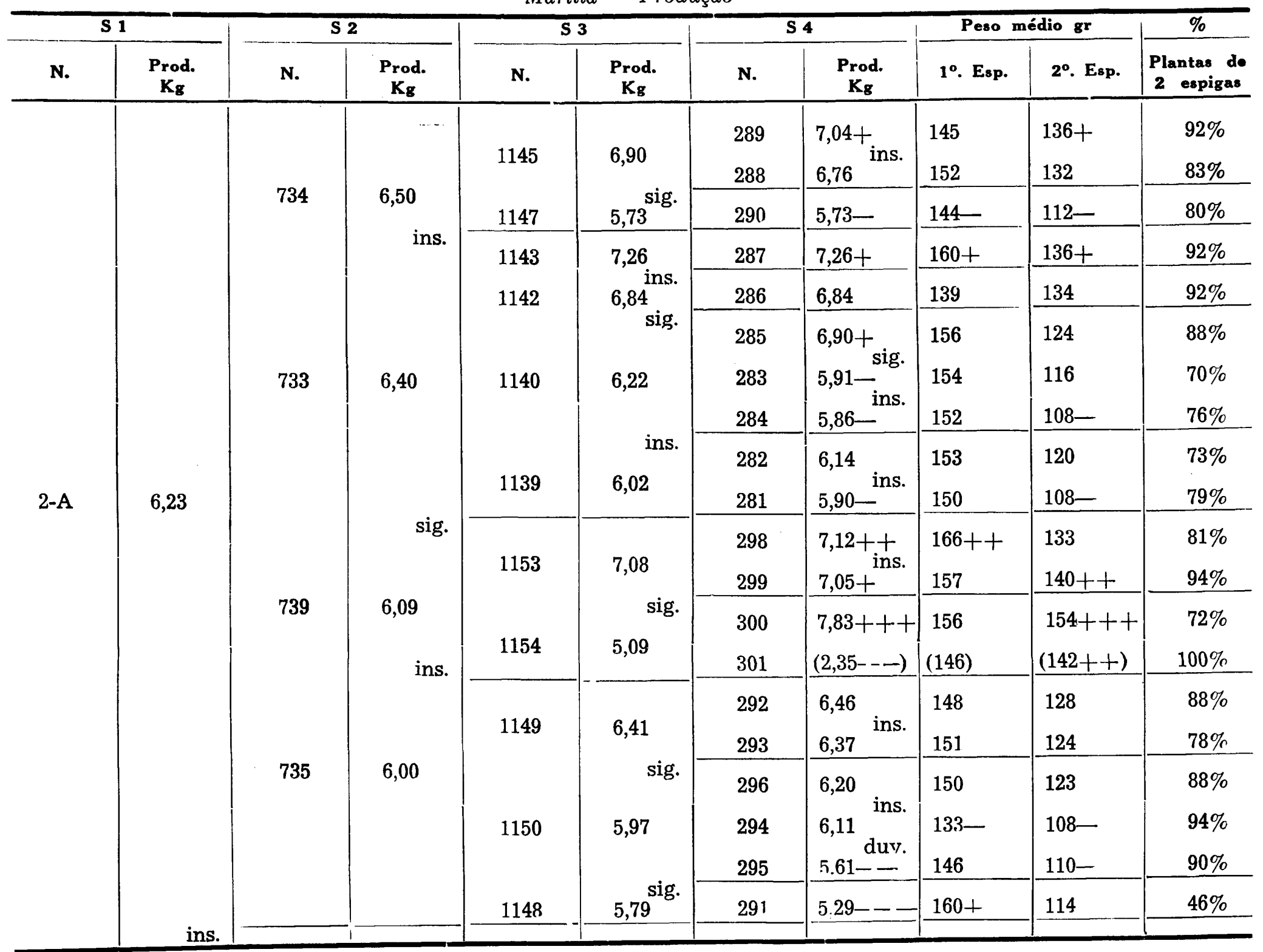

TABELA 3-A

Marília - Produção

\begin{tabular}{|c|c|c|c|c|c|c|c|c|c|c|}
\hline \multicolumn{2}{|c|}{$\mathbf{S 1}$} & \multicolumn{2}{|c|}{$\mathbf{5} 2$} & \multicolumn{2}{|c|}{$\mathbf{S} 3$} & \multicolumn{2}{|c|}{54} & \multicolumn{2}{|c|}{ Peso médio gr } & \multirow{2}{*}{\begin{tabular}{|c|}
$\%$ \\
$\begin{array}{c}\text { Plantas de } \\
2\end{array}$ espigas
\end{tabular}} \\
\hline N. & $\begin{array}{c}\text { Prod. } \\
\mathbf{K}_{\mathbf{g}}\end{array}$ & N. & $\begin{array}{c}\text { Prod. } \\
\mathbf{K g}\end{array}$ & N. & $\begin{array}{c}\text { Prod. } \\
\mathbf{K}_{\mathbf{g}}\end{array}$ & $\mathbf{N}$ & $\begin{array}{c}\text { Prod. } \\
\mathbf{K} \mathbf{g}\end{array}$ & $1^{\circ}$. Esp. & $2^{\circ}$. Esp. & \\
\hline \multirow[b]{5}{*}{$3-\mathrm{A}$} & \multirow{5}{*}{6,23} & \multirow{3}{*}{742} & \multirow{4}{*}{6,90} & 1158 & \multirow{3}{*}{$\begin{array}{c}7,54 \\
\text { ins. } \\
7,19 \text { sig. } \\
5,97\end{array}$} & 303 & $7,54+++$ & 154 & $134+$ & $93 \%$ \\
\hline & & & & 1157 & & 302 & $7,19++$ & 153 & 133 & $90 \%$ \\
\hline & & & & 1159 & & 304 & $5,97-$ & $130--$ & 113 & $92 \%$ \\
\hline & & \multirow{2}{*}{745} & & 1164 & 6,70 & 311 & 6.70 & 142 & 126 & $92 \%$ \\
\hline & & & 6,61 & 1166 & $6,53^{\operatorname{lns} .}$ & 314 & 6,53 & $134-$ & 128 & $100 \%$ \\
\hline
\end{tabular}


TABELA 4

Ipanema - Altura da Planta

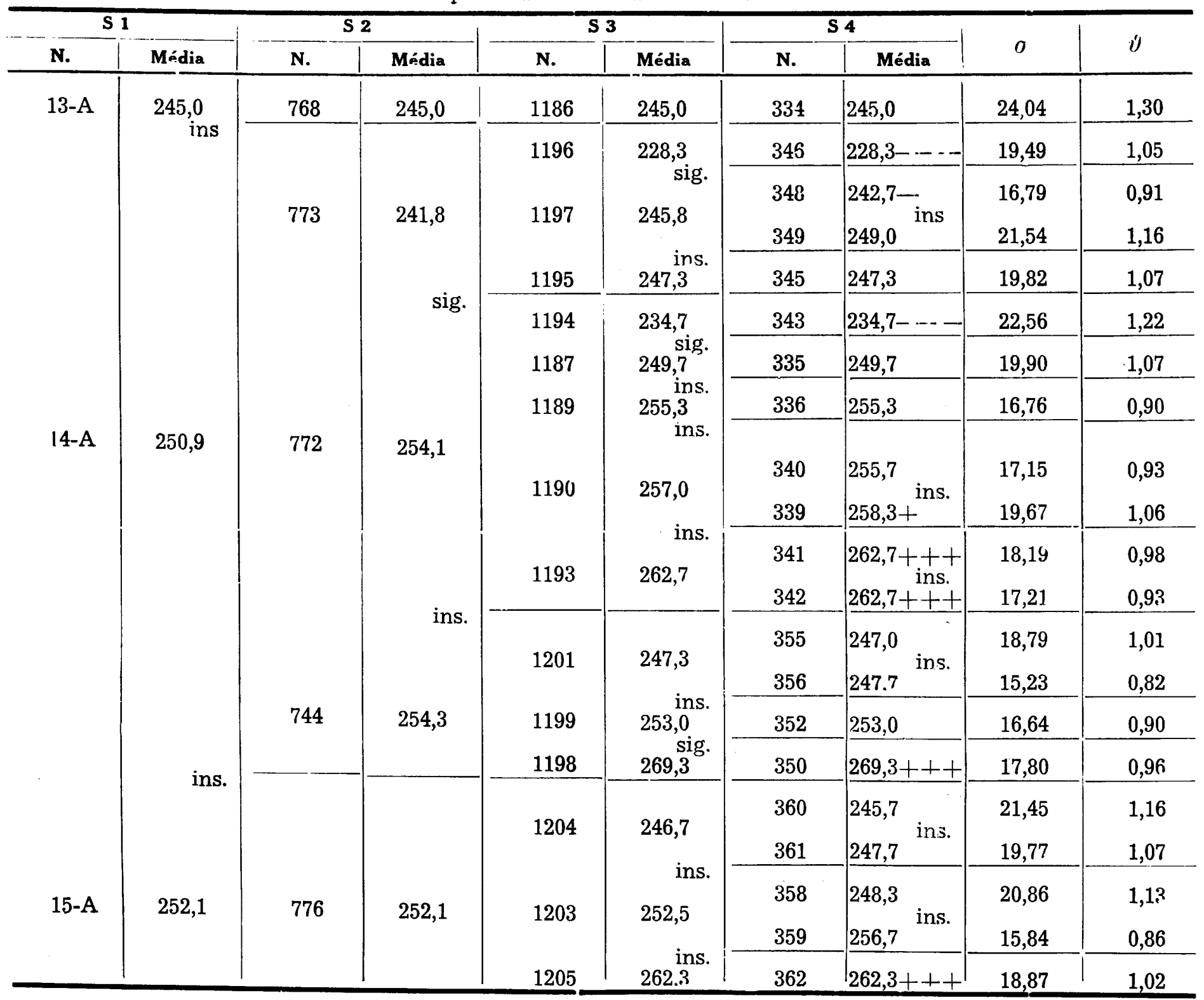


TABELA 5

Ipanema - Altura da Espiga

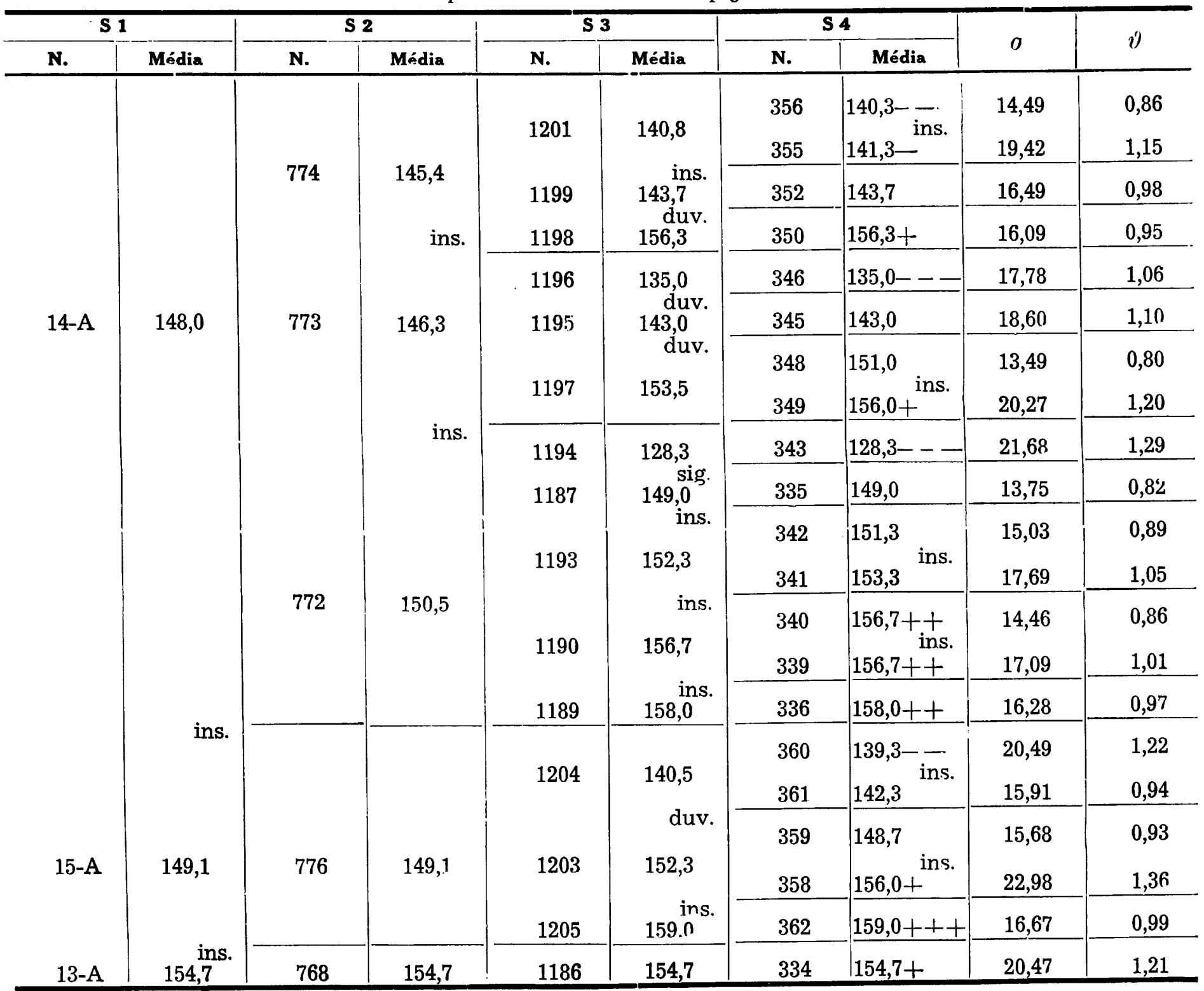


TABELA 6

Ipanema - Produção

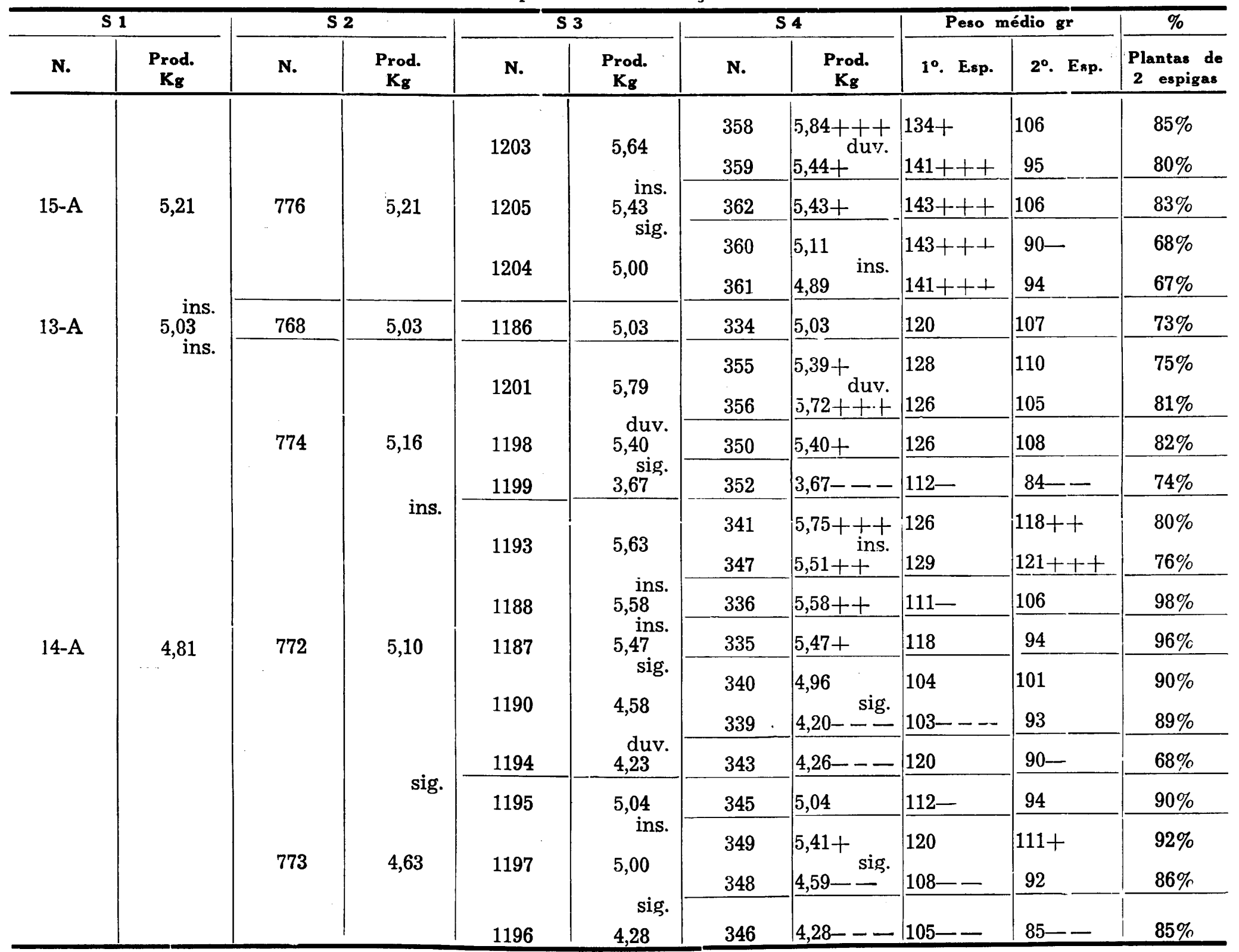


TABELA 7

Quarentão - Altura da Planta

\begin{tabular}{|c|c|c|c|c|c|c|c|c|c|c|}
\hline \multicolumn{11}{|c|}{ Quarentão Estanzuela } \\
\hline \multirow{2}{*}{ s o } & \multicolumn{2}{|c|}{ S 1} & \multicolumn{2}{|c|}{ S 2} & \multicolumn{2}{|c|}{53} & \multicolumn{2}{|c|}{ S 4} & \multirow{2}{*}{$\sigma$} & \multirow{2}{*}{$\vartheta$} \\
\hline & N. & Média & N. & Média & N. & Média & N. & Média & & \\
\hline \multirow{2}{*}{ Cruz } & \multirow{2}{*}{786} & \multirow{2}{*}{121,0} & 24 & \multirow{2}{*}{$\begin{array}{l}118,0--- \\
\text { ins. } \\
124,0\end{array}$} & - & --- & - & $-\cdots$ & 13,4 & 0,91 \\
\hline & & & 23 & & $\longrightarrow$ & --- & - & --- & 15,2 & 1,03 \\
\hline \multirow{4}{*}{ Sig } & \multirow{8}{*}{512} & \multirow{8}{*}{132,0} & \multirow{3}{*}{784} & \multirow{3}{*}{129,0} & 22 & \multirow{3}{*}{$\begin{array}{l}124,0 \\
129,0 \text { ins. } \\
134,0\end{array}$} & - & --- & 13,0 & 0,88 \\
\hline & & & & & 20 & & - & $-\cdots$ & 12,4 & 0,84 \\
\hline & & & & & 21 & & - & $-\cdots$ & 15,1 & 1,03 \\
\hline & & & & & 17 & $124,0-\overline{\text { duv. }}$ & - & & & 1,19 \\
\hline \multirow[t]{3}{*}{ Cruz } & & & 783 & 134,0 & 16 & 133,0 ins. & 二 & --- & 19,7 & 1,34 \\
\hline & & & & & $\begin{array}{l}19 \\
18\end{array}$ & $\left\{\begin{array}{l}139,0++ \\
\text { ins. } \\
139,0++\end{array}\right.$ & - & $\begin{array}{l}--- \\
--1\end{array}$ & $\begin{array}{l}12,0 \\
14,0\end{array}$ & $\begin{array}{l}0,81 \\
0,95\end{array}$ \\
\hline & & & 782 & $1350^{\text {Ins. }}$ & 14 & 129,0 & - & --- & 13,9 & 0,94 \\
\hline \multirow{2}{*}{ Ins. } & & & & & 13 & $140,0+++$ & - & --- & 15,0 & 1,02 \\
\hline & \multirow{2}{*}{508} & \multirow{4}{*}{$\begin{array}{l}134,0 \\
\text { ins. } \\
134,0\end{array}$} & \multirow{2}{*}{780} & \multirow{2}{*}{134,0} & 10 & 133,0 & - & -- & 15,3 & 1,04 \\
\hline \multirow{2}{*}{ Cruz } & & & & & 9 & 135,0 & - & --- & 11,8 & 0,80 \\
\hline & 510 & & 781 & 134,0 & 11 & $123,0--\overline{\text { sig. }}$ & 一 & - - & 20,5 & 1,39 \\
\hline \multirow{2}{*}{ Duv. } & & & & & 12 & $145,0+++$ & - & --- & 15,2 & 0,99 \\
\hline & \multirow{5}{*}{81} & \multirow{5}{*}{140,0} & 502 & 100 & 779 & j1200 & 5 & 135,0 & 14,1 & 0,96 \\
\hline \multirow{4}{*}{ Var. } & & & . & 100,0 & 182 & 100,0 & 6 & $144,0+++$ & 11,4 & 0,77 \\
\hline & & & & & & & 4 & $139,0+++$ & 16,8 & 1,14 \\
\hline & & & 501 & 141,0 & 771 & 141,0 & 1 & $141,0+++$ & 15,8 & 1,08 \\
\hline & & & & & & & 2 & $144,0+++$ & 15,5 & 1,05 \\
\hline & & & & & ntão & ein & & & & \\
\hline & & & & & 27 & 120,0 & 一 & $-\cdots$ & 14,1 & 0,95 \\
\hline & $5<4$ & 121,0 & 782 & 121,0 & 26 & 122,0 & - & $-\cdots$ & 18,2 & 1,24 \\
\hline & & & 784 & 115,0 & 34 & 155,0 & 29 & 115,0 & 10,8 & $0, \underline{73}$ \\
\hline & & & 785 & 136,0 & 37 & 136,0 & 30 & 136,0 & 16,2 & 1,10 \\
\hline & & & 38 & 123,0 & 31 & 123,0 & - & --- & 17,2 & 1,17 \\
\hline Cruz & 511 & 132,0 & 39 & 133,0 & 32 & 133,0 & - & $-\cdots$ & 13,6 & 0,93 \\
\hline & & & 29 & 139,0 & 28 & 139,0 & 一 & --- & 12,7 & 0,86 \\
\hline
\end{tabular}


TABELA 8

Quarentão - Altura da Espiga

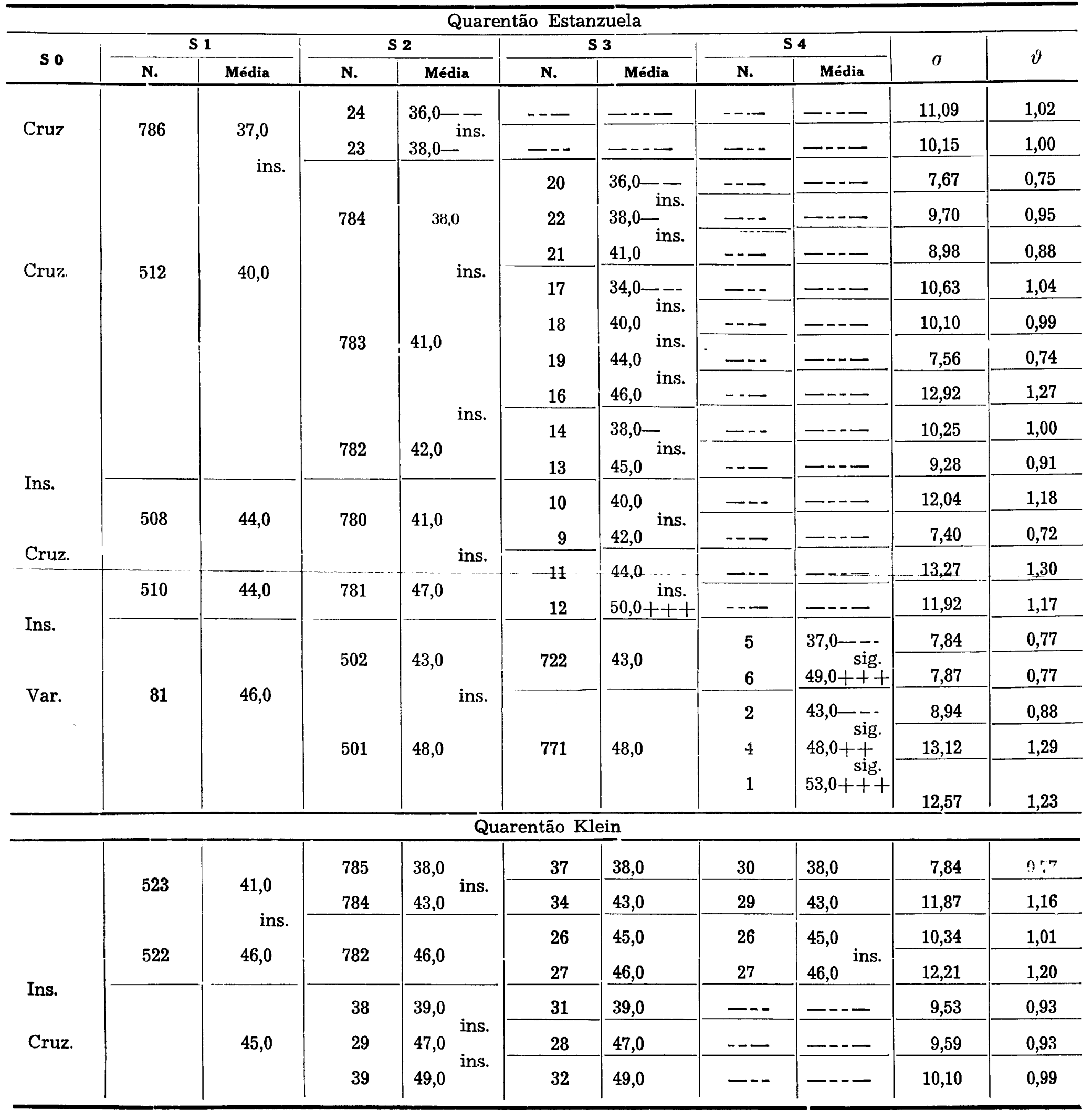


TABELA 10

Resultados da Seleção

\begin{tabular}{|c|c|c|c|c|c|c|}
\hline \multirow[b]{2}{*}{$\mathbf{N}$} & \multirow[b]{2}{*}{$\begin{array}{l}\text { Prod. } \mathbf{K}_{\mathbf{g}} \\
\text { por: } \mathbf{0 m 2}\end{array}$} & \multicolumn{2}{|c|}{ Peso médio em gr } & \multirow{2}{*}{$\begin{array}{c}\% \text { de } \\
\text { plantas de } 2 \\
\text { espigas }\end{array}$} & \multicolumn{2}{|c|}{ Média (cm) } \\
\hline & & 1a. Esp. & 2a. Esp. & & Alt. Planta & Alt. Espiga \\
\hline \multicolumn{7}{|c|}{ Marília: Seleção pela produção } \\
\hline $\begin{array}{l}300 \\
303 \\
287 \\
302 \\
298 \\
299 \\
289 \\
285\end{array}$ & $\begin{array}{l}7,83+- \\
7,54+- \\
7,26+- \\
7,19+- \\
7,12+- \\
7,05+ \\
7,04+ \\
6,90+\end{array}$ & \begin{tabular}{l|}
156 \\
154 \\
160 \\
153 \\
$166++$ \\
157 \\
145 \\
156 \\
\end{tabular} & $\begin{array}{l}154++t \\
134+ \\
136+ \\
133 \\
133 \\
140+t \\
136+ \\
124\end{array}$ & $\begin{array}{l}72 \% \\
93 \% \\
92 \% \\
90 \% \\
81 \% \\
94 \% \\
92 \% \\
88 \% \\
\end{array}$ & \begin{tabular}{|l}
$309+++$ \\
$293+++$ \\
287 \\
280 \\
288 \\
278 \\
$299+++$ \\
288 \\
\end{tabular} & $\begin{array}{l}194++ \\
184 \\
191 \\
177 \\
179 \\
173- \\
195++ \\
190+ \\
\end{array}$ \\
\hline \multicolumn{7}{|c|}{ Marília : Seleção pelo porte das plantas } \\
\hline $\begin{array}{l}306 \\
304 \\
309 \\
314 \\
310 \\
290 \\
308 \\
299 \\
283 \\
\end{array}$ & $\begin{array}{l}5,88- \\
5,97- \\
5,85- \\
6,53 \\
5,94- \\
5,73- \\
5,62- \\
7,05+ \\
5,91- \\
\end{array}$ & $\begin{array}{l}131- \\
130-- \\
128-- \\
134- \\
135 \\
144- \\
132- \\
157 \\
154\end{array}$ & $\begin{array}{l}108- \\
113 \\
109 \\
128 \\
115 \\
112- \\
102-- \\
140++ \\
116\end{array}$ & $\begin{array}{r}96 \% \\
92 \% \\
92 \% \\
100 \% \\
81 \% \\
80 \% \\
83 \% \\
94 \% \\
70 \% \\
\end{array}$ & $\begin{array}{l}258-- \\
267--- \\
267--\cdots \\
267--\cdots \\
269-- \\
277-- \\
278-- \\
278-- \\
278--\end{array}$ & $\begin{array}{l}155--- \\
162-- \\
163-- \\
164-- \\
167-- \\
173 \\
166-- \\
173- \\
180\end{array}$ \\
\hline \multicolumn{7}{|c|}{ Ipanema : Seleçã o pela produção } \\
\hline $\begin{array}{l}358 \\
341 \\
356 \\
336 \\
342 \\
\end{array}$ & $\begin{array}{l}5,84+++ \\
5,75+++ \\
5,72+++ \\
5,58++ \\
5,51++\end{array}$ & $\begin{array}{l}134 \\
126 \\
126 \\
111- \\
129 \\
\end{array}$ & $\begin{array}{l}106 \\
118++ \\
105 \\
106 \\
121+t+\end{array}$ & $\begin{array}{l}85 \% \\
80 \% \\
81 \% \\
98 \% \\
16 \% \\
\end{array}$ & $\mid \begin{array}{l}248 \\
263+++ \\
248 \\
255 \\
263+++\end{array}$ & $\begin{array}{l}156+ \\
153 \\
140-- \\
158++ \\
151\end{array}$ \\
\hline \multicolumn{7}{|c|}{ Ipanema : Seleção pelo porte das plantas } \\
\hline $\begin{array}{l}346 \\
343 \\
348 \\
360 \\
356 \\
\end{array}$ & $\begin{array}{l}4,28--- \\
4.26--- \\
4,59-- \\
5,11 \\
5.72+++\end{array}$ & $\begin{array}{l}105-- \\
120 \\
108-- \\
143+++ \\
126\end{array}$ & $\begin{array}{l}05-- \\
90- \\
92 \\
94 \\
105 \\
\end{array}$ & \begin{tabular}{|l}
$85 \%$ \\
$68 \%$ \\
$86 \%$ \\
$68 \%$ \\
$81 \%$ \\
\end{tabular} & $\begin{array}{l}228--- \\
235--- \\
243- \\
246 \\
248\end{array}$ & $\begin{array}{l}135--- \\
128--- \\
151 \\
139-- \\
140--\end{array}$ \\
\hline \multicolumn{7}{|c|}{ Média Geral } \\
\hline $\begin{array}{l}\text { Marília } \\
\text { Ipanema } \\
\text { I A. } 3531\end{array}$ & $\begin{array}{l}6,23 \\
5,09 \\
6,61\end{array}$ & $\begin{array}{l}146 \\
122 \\
144 \\
\end{array}$ & $\begin{array}{l}1.22 \\
101 \\
124\end{array}$ & $\begin{array}{l}85 \% \\
82 \% \\
54 \%\end{array}$ & $\begin{array}{l}284 \\
251 \\
271\end{array}$ & $\begin{array}{l}181 \\
149 \\
169 \\
\end{array}$ \\
\hline
\end{tabular}

